\title{
RESPOSTA DAS ENZIMAS ANTIOXIDANTES EM LINHAGENS DO FUNGO Aspergillus sp. NA PRESENÇA DO METAL PESADO CÁDMIO
}

\author{
ANDREA GUELFI
}

Dissertação apresentada à Escola Superior de Agricultura "Luiz de Queiroz", Universidade de São Paulo, para obtenção do título de Mestre em Agronomia, Área de Concentração: Genética e Melhoramento de Plantas.

\author{
PIR A C I C A B A \\ Estado de São Paulo - Brasil
}

Novembro - 2001 


\title{
RESPOSTA DAS ENZIMAS ANTIOXIDANTES EM LINHAGENS DO FUNGO Aspergillus sp. NA PRESENÇA DO METAL PESADO CÁDMIO
}

\author{
ANDREA GuELFI \\ Engenheiro Agrônomo \\ Orientadora: Profa. Dra. SILVIA MARIA GUERRA MOLINA
}

Dissertação apresentada à Escola Superior de Agricultura "Luiz de Queiroz", Universidade de São Paulo, para obtenção do título de Mestre em Agronomia, Área de Concentração: Genética e Melhoramento de Plantas.

\author{
PIRACICABA \\ Estado de São Paulo - Brasil \\ Novembro - 2001
}


Dados Internacionais de Catalogação na Publicação (CIP)
DIVISÃO DE BIBLIOTECA E DOCUMENTAÇÃO - ESALO/USP

\section{Guelfi, Andrea}

Resposta das enzimas antioxidantes em linhagens do fungo Aspergillus sp. na presença do metal pesado cádmio / Andrea Guelfi. - - Piracicaba, 2001.

60 p. : il.

Dissertação (mestrado) - - Escola Superior de Agricultura Luiz de Queiroz, 2001.

Bibliografia.

1. Análise enzimática 2. Aspergillus 3. Ascomiceto 4. Cádmio 5. Polvição ambiental I. Título

CDD 589.24

\section{"Permitida a cópia total ou parcial deste documento, desde que citada a fonte - $O$ autor"}


Aos meus avós Durval e Adelina, pelo carinho. Aos meus pais Walter e Selles, pelo apoio irrestrito.

\section{DEDICO}




\section{AGRADECIMENTOS}

À Profa. Dra. Silvia Maria Guerra Molina pela orientação, amizade e apoio durante a realização deste trabalho;

Ao Prof. Dr. Ricardo Antunes de Azevedo pelo apoio e pelas enriquecedoras discussões;

Aos Prof João Lúcio de Azevedo e Aline Pizzirani Kleiner pelo apoio.

Aos colegas e amigos do laboratório de microrganismos, especialmente a Ágata, Fernando G. B., Gisa, Joelma, Júlia, Mayra, Pipa, Zezo e Wellington;

Aos colegas e amigos do laboratório de genética e bioquímica de plantas, especialmente o Renato, Guilherme, Ricardo, Leonardo, Patrícia e Salete;

Aos funcionários da ESALQ/USP que de alguma forma contribuíram para a realização deste trabalho, especialmente a Silvana, Valdir, Fernando, Neuza, Léia e Adriana;

Aos professores do Departamento de Genética pela colaboração;

Ao CNPq pela concessão da bolsa de estudo. 


\section{SUMÁRIO}

Página

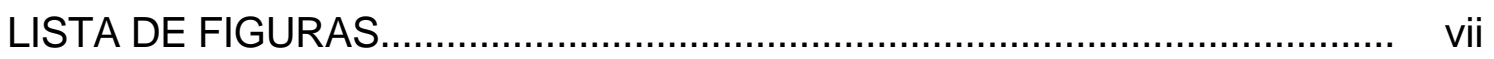

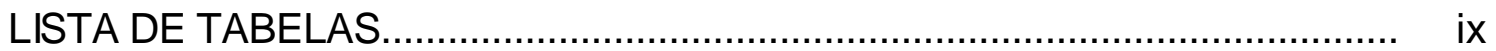

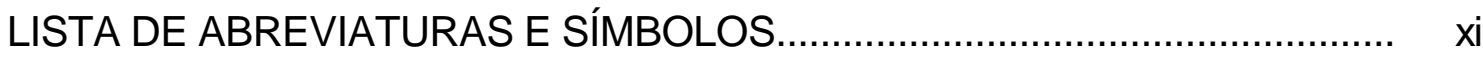

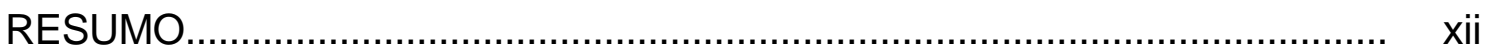

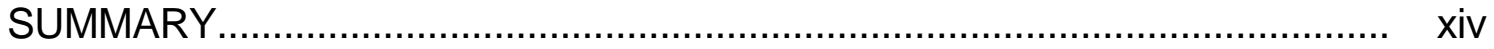

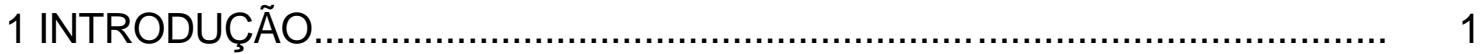

2 REVISÃO DE LITERATURA............................................................ 2

2.1 Efeitos do cádmio no ambiente ........................................................... 2

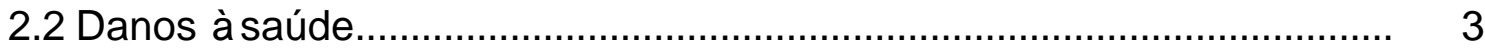

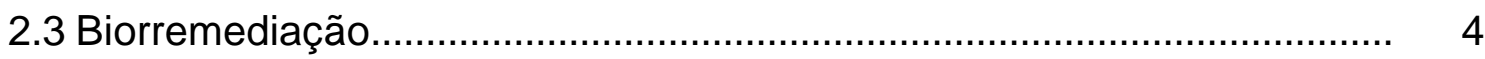

2.4 Espécies reativas de oxigênio...................................................... 6

2.4.1 Superóxido dismutase .................................................................. 8

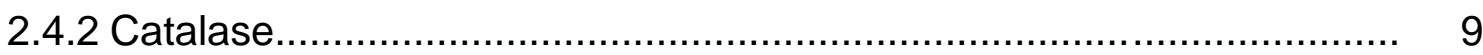

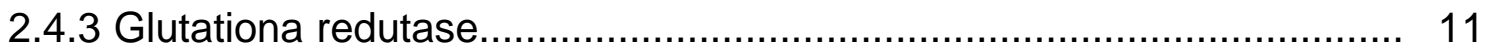

2.4.4 Guaiacol peroxidase ...................................................... 12

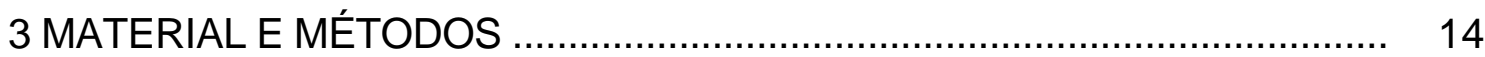

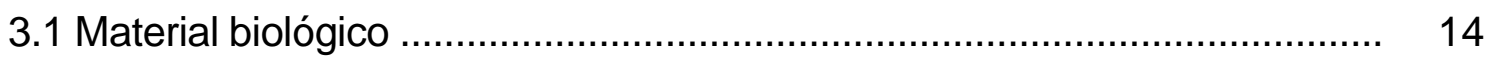

3.2 Meios de cultura .......................................................................... 14

3.2.1 Meio Completo ................................................................. 14

3.2.2 Meio Completo líquido ......................................................... 15

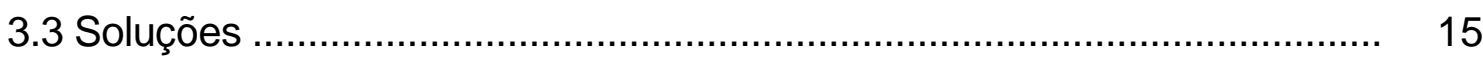

3.3.1 Solução de vitaminas .............................................................. 15 


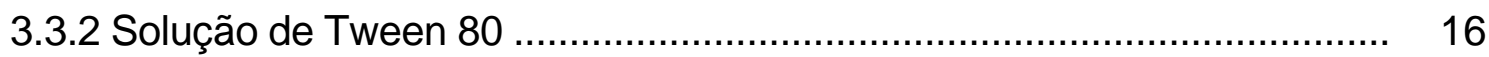

3.3.3 Solução Salina ........................................................................... 16

3.4 Experimento básico ..................................................................... 16

3.5 Extração das enzimas .............................................................. 18

3.6 Determinação de proteínas ........................................................... 18

3.6.1 Gel de proteínas SDS-PAGE ....................................................... 18

3.6.2 Atividade da catalase ............................................................ 19

3.6.3 Atividade da superóxido dismutase ............................................. 19

3.6.4 Determinação das isoenzimas de SOD ............................................ 20

3.6.5 Atividade da glutationa redutase ............................................... 20

3.6.6 Atividade de guaiacol peroxidase ................................................ 21

3.7 Análise estatística ............................................................................. 21

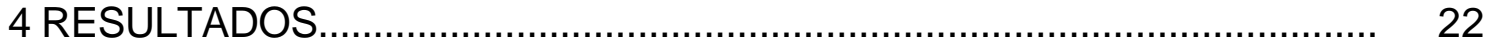

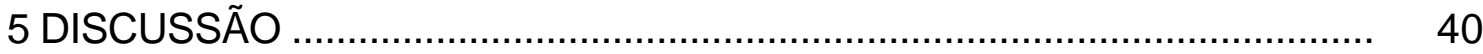

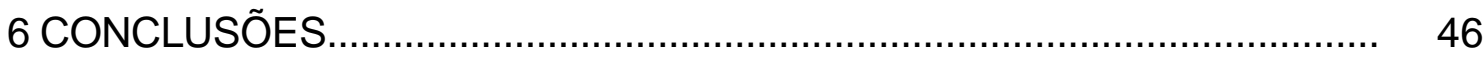

6.1 Linhagem MSE de A. nidulans ......................................................... 46

6.2 Linhagem CadG1 de Aspergillus sp.................................................. 46

6.3 Considerações finais .......................................................................... 4

REFERÊNCIAS BIBLIOGRÁFICAS........................................................ 48 


\section{LISTA DE FIGURAS}

Página

1 Efeito das dosagens de cádmio no peso seco do micélio da linhagem MSE em diferentes períodos de tempo

2 Efeito das dosagens de cádmio nas proteínas totais do micélio da linhagem MSE em diferentes períodos de tempo

3 Gel SDS - PAGE na linhagem MSE

4 Caracterização das isoenzimas da SOD, na linhagem MSE

5 Gel de atividade da SOD, na linhagem MSE

6 Gel de atividade de CAT, na linhagem MSE

7 Gel de atividade da guaiacol peroxidase, na linhagem MSE

8 Efeito das dosagens de cádmio na atividade de GR no micélio da linhagem MSE em diferentes períodos de tempo

9 Gel de proteínas SDS comparando as linhagens MSE e CadG1 
10 Gel de atividade da enzima SOD, nas linhagens MSE e CadG1

11 Gel de atividade da enzima CAT, nas linhagens MSE e CadG1

12 Atividade de guaiacol peroxidase na linhagem CadG1 ....................... 37

13 Efeito das dosagens de cádmio na atividade de GR no micélio da linhagem MSE e CadG1 no período de 24 horas 


\section{LISTA DE TABELAS}

Página

1 Análise de variância dos dados provenientes do peso seco do micélio da linhagem MSE

25

1.1 Análise de variância da tabela 1 fixando o fator concentração.

1.2 Análise de variância da tabela 1 fixando o fator hora 26

2 Análise de variância dos dados provenientes das proteínas totais do micélio da linhagem MSE.

2.1 Análise de variância da tabela 2 fixando o fator concentração

3 Análise de variância dos dados provenientes da atividade de GR do micélio da linhagem MSE 
4 Análise de variância dos dados provenientes da atividade de GR do micélio das linhagens MSE e CadG1 no período de 24 horas .....

4.1 Análise de variância da tabela 4 fixando o fator concentração. 


\section{LISTA DE SIGLAS, ABREVIATURAS E SÍMBOLOS}

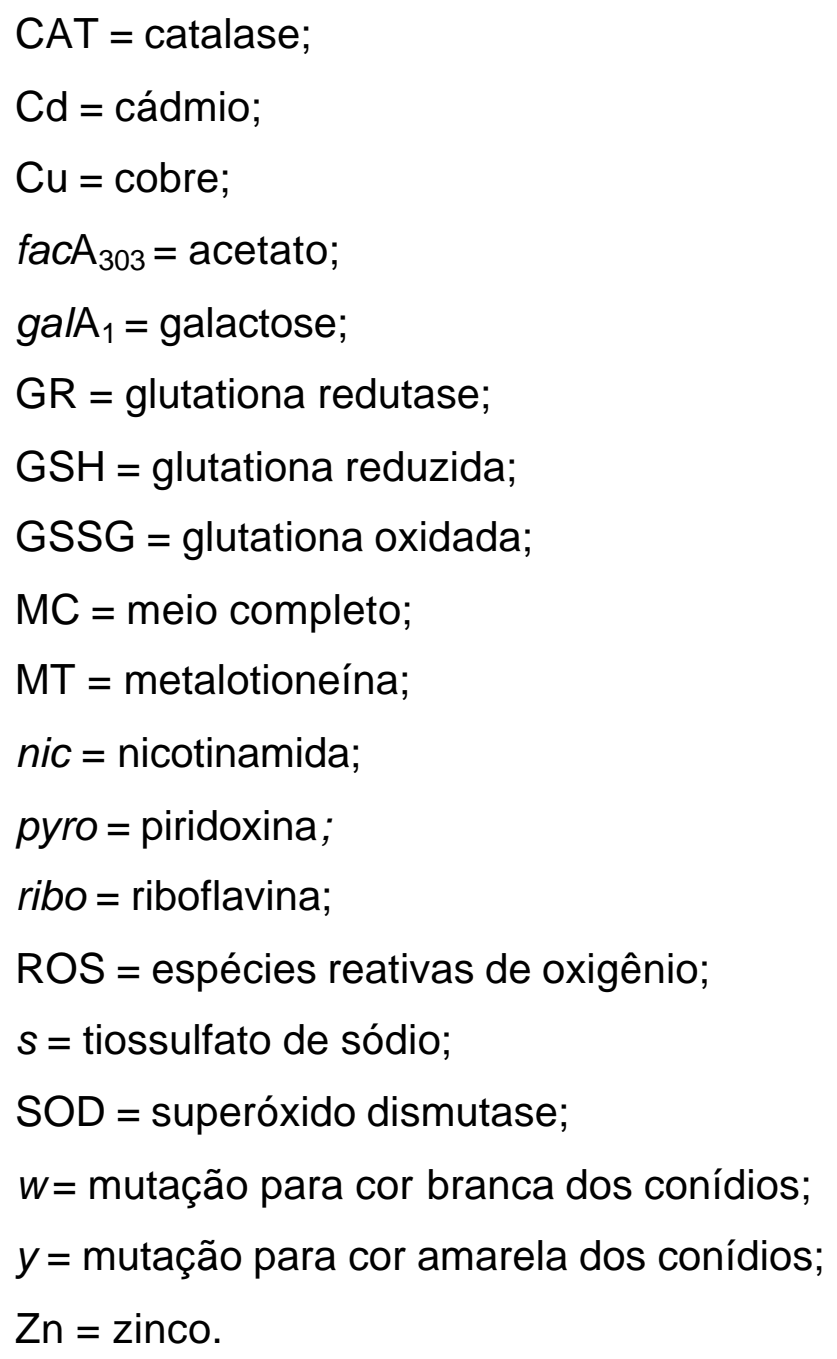




\title{
RESPOSTA DAS ENZIMAS ANTIOXIDANTES EM LINHAGENS DO FUNGO Aspergillus sp. NA PRESENÇA DO METAL PESADO CÁDMIO
}

\author{
Autora: ANDREA GUELFI \\ Orientadora: Profa. SILVIA MARIA GUERRA MOLINA
}

\section{RESUMO}

A contaminação de ambientes aquáticos por metais pesados é uma ameaça cada vez mais presente em muitos ecossistemas, especialmente próximo a áreas industriais e urbanas. Utilizando a capacidade que os fungos têm de biosorver metais pesados alguns pesquisadores preocupados com esse problema, começaram a estudar técnicas de biorremediação usando microrganismos, dentre eles os fungos. Essa técnica consiste em remover íons tóxicos do ambiente com o auxílio de organismos vivos. Porém, esses íons promovem a formação de espécies reativas de oxigênio (ROS), as quais estimulam a produção de enzimas responsáveis por sua desintoxicação, dentre elas as peroxidases, superóxido dismutase (SOD), catalase (CAT), glutationa redutase (GR), guaiacol peroxidase, e outras. Este trabalho teve como proposta estudar variações nas enzimas antioxidantes em resposta à administração do $\mathrm{Cd}$ em uma linhagem do fungo Aspergillus nidulans (MSE), por possuir marcadores em todos os cromossomos e ser considerada um modelo de 
estudos genéticos. Paralelamente, uma linhagem mutante denominada CadG1 foi selecionada por ser tolerante ao $\mathrm{Cd}$ e incluída nos estudos de resposta ao $\mathrm{Cd}$. Foram estudadas as respostas antioxidantes destas linhagens na presença do Cd. O primeiro propósito foi conhecer o comportamento enzimático da linhagem MSE em resposta ao $\mathrm{Cd}$, e para isso foi realizado um experimento básico dividido em duas partes; a primeira envolvendo a determinação de peso seco e a segunda com o propósito de estudar as atividades enzimáticas, nas concentrações de $0,0,005,0,01,0,025$ e $0,05 \mathrm{mM}$ de $\mathrm{CdCl}_{2}$, e períodos de tempo de 6, 9, 12 e 24 horas, a partir de um crescimento de 12 horas em meio completo (MC). O segundo propósito do trabalho consistiu numa comparação entre a linhagem MSE, previamente caracterizada, e a linhagem mutante resistente ao Cd (CadG1), utilizando-se concentrações de 0, 0,05, 0,025 e 0,05 $\mathrm{CdCl}_{2}$, pelo período de 24 horas. A linhagem MSE apresentou resposta positiva para as enzimas CAT e GR com o aumento do Cd, a enzima SOD apresentou um aumento não significativo e ainda, houve uma redução significativa na quantidade total de proteínas na concentração de $0,05 \mathrm{mM}$. O período de tempo que melhor expressou a resposta enzimática ao $\mathrm{Cd}$ foi de 24 horas. A linhagem CadG1, tolerante ao $\mathrm{Cd}$, mostrou um aumento de 3,6 vezes na enzima GR, enquanto a MSE aumentou em 2 vezes, no mesmo experimento. Houve uma resposta negativa da CadG1 em relação ao aumento do Cd para a enzima CAT, e não houve resposta significativa para a SOD. Ambas as linhagens não apresentaram a enzima guaiacol peroxidase, tanto no controle como na presença do $\mathrm{Cd}$. Os resultados obtidos sugerem que na linhagem mais sensível ao Cd, a MSE, este metal induziu a formação de peróxido de hidrogênio e, por conseqüência, induziu a atividade de CAT e, em menor escala, a GR. Na linhagem mais tolerante, a CadG1, o mecanismo principal de resposta antioxidante foi a enzima GR, sugerindo que ocorreu eliminação de ROS por meio da glutationa reduzida. 


\section{ANTIOXIDANT ENZYME RESPONSES OF Aspergillus nidulans sp. TO THE HEAVY METAL CADMIUM.}

Author: ANDREA GUELFI

Adviser: Profa. SILVIA MARIA GUERRA MOLINA

\section{SUMMARY}

The contamination of aquatic environments by heavy metals has became a serious threat to distinct ecossystems, particularly those nearby urban and industrial areas. Based on the ability of fungi to uptake heavy metals from the environment, research has been focused on bioremediation techniques involving microrganisms such as fungi. Such technique involve the removal of bxic ions from the environment by living organisms. These toxic ions can induce the formation of reactive oxygen species (ROS), which can stimulate enzymes such as, peroxidases, superoxide dismutase (SOD), catalase (CAT), glutathione reductase (GR), guaiacol peroxidase, among others, that involved in the defense system. The aim of this work was to study the response of antioxidant enzymes of Aspergillus nidulans to Cd exposure. The strain used was the MSE which contains several markers in all cromossomes and has been studied in detail. A Cd-resistant strain, denominated CadG1, was isolated and also used in this study. The first aspect studied was the enzimatic response of the strain MSE to Cd exposure. 
Initially, the dry weight was determined for MSE in the presence of Cd. After initial growth for $12 \mathrm{~h}$ in complete medium, MSE was further grown in the presence of varying concentrations of $\mathrm{CdCl}_{2}(0,0.005,0.01,0.025$ and $0.05 \mathrm{mM})$ for $6,9,12$ and 24 hours. The activities of antioxidant enzymes were analysed in the different treatments. In a separate experiment using $0,0.05,0.025$ and $0.05 \mathrm{mM} \mathrm{CdCl}_{2}$ for $24 \mathrm{~h}$, the responses of MSE and CadG1 to Cd exposure were compared. MSE exhibited increased CAT and GR activities in response to Cd, whereas SOD also exhibited some increase in activity, but not significant. Soluble protein content was also shown to be reduced in $0.05 \mathrm{mM} \mathrm{CdCl}_{2}$ treatment. The $24 \mathrm{~h} \mathrm{CdCl}_{2}$ treatment was shown to be effective to analysed the response to Cd stress. The Cdresistant CadG1 strain exhibited a 3.6-fold increase in GR activity, while in MSE the increase was in the range of 2 -fold. For CAT a negative response was observed for CadG1 whereas for SOD a significant change in activity was not observed. In both, MSE and CadG1 strains, the activity of guaiacol peroxidase was not observed. The results suggest that $\mathrm{Cd}$ induces the formation of hydrogen peroxide in MSE, inducing CAT activity and to a lesser extent, GR activity. However, for the Cd-resistant CadG1 strain, the main effect was observed for $\mathrm{Gr}$ activity, which was enhanced, suggesting that in this mutant the dismutation of ROS is mainly due to the mechanism involving GR and reduced glutathione. 


\section{INTRODUÇÃO}

O aumento nas atividades industriais tem intensificado a poluição ambiental e a deterioração de alguns ecossistemas com o acúmulo de poluentes tais como metais pesados, compostos sintéticos, resíduos líqüidos nucleares, etc.

Decorrente disto, tornou-se relevante a busca de um modelo para estudar em células eucarióticas, os mecanismos bioquímicos associados à expressão de genes induzidos pelo estresse devido à exposição a metais pesados, bem como o desenvolvimento de tolerância aos mesmos. Para tanto escolheurse o fungo filamentoso $A$. nidulans e ensaios de exposição ao $\mathrm{Cd}$. $\mathrm{O}$ Aspergillus é um fungo capaz de crescer numa ampla variedade de substratos, muitos dos quais induzem a geração, em níveis elevados, de espécies reativas de oxigênio (ROS). Dentre esses indutores podem-se ressaltar os ácidos graxos, etanol, glicerol e ácido úrico.

Entender o comportamento bioquímico de um fungo Ascomiceto, pode contribuir para se conhecer melhor a origem da grande capacidade de sorção que os fungos possuem e suas possíveis aplicações em sistemas de biorremediação. Além disso pode nos fornecer informações a respeito do comportamento de suas principais enzimas antioxidantes, sua salvaguarda para evitar o estresse oxidativo causado pelas ROS decorrentes da exposição ao metal pesado cádmio. A importância de estudar esse metal, como detalhado adiante, deve-se ao intenso efeito tóxico causado nos seres vivos associada à sua ampla liberação no ambiente, devido às atuais atividades agroindustriais. 


\section{REVISÃO DE LITERATURA}

\subsection{Efeito do cádmio no ambiente}

O termo "metal pesado" é aplicado a um grupo heterogêneo de elementos, incluindo metais, semi-metais e não metais (Melo et al., 1997), que possuem número atômico maior que 20 ou peso específico maior que $5{\mathrm{~g} . \mathrm{cm}^{-3}}^{-3}$ (Malavolta, 1994).

De todos os metais pesados poluentes, o $\mathrm{Cd}$ é um dos mais tóxicos (Chen \& Kao, 1995a; Kefala, 1999) para os seres humanos, animais e plantas sendo entre esses elementos, o que tem apresentado as mais altas taxas de emissão para o ambiente nas últimas décadas (Nascimento \& Pereira, 1997). A poluição do ambiente com metais pesados tóxicos ocorre em todo o mundo, e deve-se ao atual modelo de avanço industrial (Dönmez \& Aksu, et al. 1999).

$O$ aumento nas atividades industriais tem intensificado a poluição ambiental e a deterioração de alguns ecossistemas com o acúmulo de poluentes tais como metais pesados, compostos sintéticos, resíduos líqüidos nucleares, etc. (Veglio \& Beolchini, 1997). Tais atividades incluem a mineração de $\mathrm{Zn}$, fundição, utilização de lodo de esgoto para fertilização na agricultura (Chaoui et al., 1997), gases liberados pela combustão de combustíveis fósseis, pesticidas (Gimeno-García et al., 1996 e Lagriffoul et al., 1998), aplicação de fertilizantes fosfatados (Chen \& Kao, 1995a; Galli et al., 1996 e Iretskaya et al., 1998), fertilizantes com impurezas (Schickler \& Caspi, 1999), processos industriais (Malan \& Farrant, 1998), queimadas e vazamentos (Chen \& Kao, 1995a), fabricação de baterias de automóveis (Prasad, 1995; Kefala et al., 
1999), aplicações militares, aeroespaciais, estabilização de plásticos e formulação de pigmentos entre outros (Prasad, 1995).

As atividades de mineração, metalurgia (Kefala et al., 1999), indústria têxtil e de placas de circuito impresso (Waihung et al., 1999) constituem uma das maiores fontes de contaminação da água por metais pesados. Além disso, as indústrias vêm promovendo o aumento do uso do cádmio nas placas de componentes eletrônicos (Kefala et al., 1999; Waihung et al., 1999), ligas, pigmentos, estabilizadores para catálise e semi-condutores e em tubo de fósforo para TV (Kefala et al., 1999).

O cádmio tem uma meia-vida de aproximadamente dez anos, o que essencialmente o torna uma toxina cumulativa, e não há tratamentos efetivos comprovados contra a intoxicação crônica com cádmio. Acumula-se primeiramente no fígado e nos rins e pode se ligar às metalotioneínas (MT), as quais constituem proteínas de baixo peso molecular com elevada afinidade por metais pesados como o Cd, Cu e Zn (Waalkes, 2000).

\subsection{Danos à saúde}

Tem sido extensivamente analisada a tolerância ao Cd numa grande variedade de organismos, devido à sua elevada toxicidade e pelo fato de não ser um elemento essencial (Cooley et al., 1986). Quando submetidos a prolongadas exposições à este metal, humanos e animais sofrem disfunções renais, desmineralização dos ossos (Ghoshroy et al., 1998), enfisemas pulmonares, destruição de eritrócitos, danos nos testículos, hipersensibilidade a doenças cardíacas (Lee et al., 1976), gastroenterite, câncer e hipertensão (Rossi et al., 1998). Administrado por via oral, pode induzir aumentos nas ocorrências de leucemia em ratos e linfoma em certas linhagens de camundongos (Waalkes, 2000). 


\subsection{Biorremediação}

A biorremediação de metais pesados tem recebido uma grande atenção recentemente, não apenas como novidade científica mas também como um aplicação potencial na indústria. Os microrganismos incluindo bactérias, algas, fungos filamentosos e leveduras são biorremediadores eficientes, removendo metais via mecanismos ativos ou passivos (Dönmez \& Aksu, 1999) e podem acumular eficientemente os metais pesados do ambiente (Gadd, 1990).

Existem técnicas disponíveis utilizadas para a remoção de metais pesados dos efluentes das indústrias e são compostas pelo emprego de técnicas de precipitação química, troca iônica, processos eletroquímicos e (ou) processos de membrana (Kefala et al., 1999; Kapoor et al, 1999), processos de osmose reversa (Kapoor et al, 1999), oxidação e redução químicas, filtragem, tratamento eletroquímico, evaporação ou extração por solventes (Waihung et al, 1999), no entanto, o custo destes processos é muito elevado (Veglio \& Beolchini, 1997).

A necessidade de métodos econômicos e eficientes para a remoção dos metais tem resultado no desenvolvimento de novas tecnologias de separação (Kefala et al., 1999). Como exemplo, pode-se citar as técnicas biológicas para remoção de chumbo dos efluentes as quais podem oferecer uma alternativa mais eficiente do que os processos físico-químicos convencionais (Waihung et al, 1999).

Embora muitos mecanismos diferentes atuem simultaneamente durante a bioacumulação e a biosorção, apenas alguns foram claramente identificados (Gadd \& White 1993), os quais envolvem a remoção dos metais via mecanismos ativos ou passivos, respectivamente (Dönmez \& Aksu, 1999).

A biosorção é baseada na capacidade dos metais de se ligarem a vários materiais biológicos, tais como algas, leveduras, fungos e bactérias (Veglio \& Beolchini, 1997) e apresenta interesse para a indústria devido àcapacidade de remoção de metais pesados dos efluentes pelos microrganismos (Kefala et al., 
1999), por exemplo, a remoção de chumbo por fungos filamentosos (Waihung et al, 1999). Este método é independente do ciclo metabólico do microrganismo e é conhecido também por captação passiva (Kapoor et al, 1999; Dönmez \& Aksu, 1999).

A abundante biomassa de fungos produzida como um sub-produto nos processos industriais em larga escala pode ser uma fonte mais economicamente viável de biosorventes de metais. A conversão de resíduo de biomassa em biosorvente de metais não apenas reduz drasticamente o custo de produção do biosorvente, mas também reduz o custo de disposição do resíduo de biomassa proveniente de indústrias, como por exemplo os fungos utilizados na produção de ácidos orgânicos (Waihung et al, 1999; Kapoor et al., 1999). A utilização de culturas em crescimento pode evitar a necessidade de uma etapa distinta, adicional, para a produção de biomassa.

Na biosorção os microrganismos seqüestram o metal através de ligações de superfície, entretanto, no processo de bioacumulação, os metais são concentrados através de uma combinação de reações de superfície como precipitações e formação de complexos intra e extracelulares. Porém, existem limitações práticas significativas para sistemas que empregam a bioacumulação, como a inibição do crescimento celular quando a concentração dos íons dos metais torna-se muito elevada, ou a elevada toxicidade dos resíduos hídricos como, extremos de $\mathrm{pH}$ e altas concentrações de sais. O processo ativo de bioremoção também requer fornecimento de nutrientes adequados, aeração e temperatura para o crescimento dos microrganismos.

Entretanto, o fato de que muitos locais onde se realizam tratamentos convencionais de esgotos acabem se tornando habitats de microrganismos, sugere que tais limitações não impossibilitam sua aplicação em sistemas envolvendo a bioremoção de metais pesados (Dönmez \& Aksu, 1999). 


\subsection{Espécies reativas de oxigênio}

Espécies reativas de oxigênio (ROS) como os radicais superóxido $\left(\mathrm{O}_{2}^{-\bullet}\right)$, peróxido de hidrogênio $\left(\mathrm{H}_{2} \mathrm{O}_{2}\right)$, radicais hidroxila $\left(\mathrm{OH}^{*}\right)$ e oxigênio "singlet" $\left({ }^{1} \mathrm{O}_{2}\right)$ são um produto inevitável do metabolismo dos organismos aeróbicos (Angelova et al., 2000), e provocam "estresse oxidativo" devido à sua ação tóxica e mutagênica sobre as células (Angelova et al., 2000; Mallick \& Mohn, 2000). Os íons dos metais pesados são capazes de causar danos oxidativos tanto diretamente, agindo como redutores e assim produzindo as ROS, ou indiretamente, inativando os acumuladores de radicais livres como as glutationas e metalotioneínas (Mannazzu et al., 2000).

Nos organismos aeróbicos as vantagens energéticas utilizando 0 oxigênio molecular como um oxidante terminal na respiração são significativas, entretanto, a presença do oxigênio no ambiente celular constitui-se numa ameaça constante æ̀ suas próprias estruturas e processos. Este fato ocorre devido a formação das ROS (Mallick \& Mohn, 2000), que podem se tornar altamente destrutivas para células e tecidos se sua produção não for estritamente controlada (Rice-Evans et al., 1991). Devido ao consumo de quase 90\% do oxigênio da célula, as mitocôndrias constituem a maior fonte de ROS nas células (Cardoso et al., 1998), no entanto, estas espécies reativas desempenham também o papel de destruir potenciais patógenos e, por isso, ocorrem também em células que promovem a fagocitose (Jamieson et al., 1996).

Em plantas, a produção das ROS é estimulada por vários fatores ambientais de estresse como a exposição a níveis elevados de luminosidade, seca, metais pesados, elevada concentração de sais, extremos de temperatura, radiação UV, poluição do ar, herbicidas, estresse físico e mecânico e também como resposta aos estresses bióticos tais como o ataque de patógenos (Mallick \& Mohn, 2000). 
Como todo organismo aeróbico, os fungos também sofrem com os efeitos tóxicos do oxigênio molecular. As ROS causam danos nos componentes celulares oxidando os lipídios (Bhattacharjee, 1998), proteínas e ácidos nucléicos (Angelova et al., 2000). Para combatê-las, as células dos fungos possuem tanto defesas antioxidantes enzimáticas, como, catalases, peroxidases e superóxido dismutases (Tekchandani,1998; Calera et al., 2000; Noventa-Jordão et al., 1999; Angelova et al., 2000), como não enzimáticas, envolvendo a glutationa, tiredoxina e poliaminas, entre outras (Calera et al., 2000). A exposição dos microrganismos aeróbicos aos mais variados fatores de estresse, tais como calor, agentes oxidantes, tratamento com drogas, raio $\mathrm{X} \mathrm{e}$ radiação UV, vem sendo associada à indução na síntese de enzimas antioxidantes (Angelova et al., 2000).

A levedura Saccharomyces cerevisiae, por exemplo, responde à presença de concentrações tóxicas do íon cobre através de diversos mecanismos de defesa, tais como, aumento da síntese de metalotioneínas e enzimas antioxidantes, e através da ativação de funções vacuolares (Mannazzu et al., 2000). Recentemente, foi demonstrado nesses organismos que o gene YCF1 está envolvido com o transporte do metal para o vacúolo, concluindo-se que esta via contribui substancialmente para a desintoxicação do cádmio (Penninckx, 2000).

Entretanto, os estudos das respostas celulares aos estresses metabólicos não são apenas um tópico para microbiologistas e ecologistas desejando entender os mecanismos celulares básicos, apesar de sua relevância, mas também um assunto crucial para a área de tecnologia microbiana a qual tem que manter a viabilidade metabólica e vitalidade das linhagens utilizadas nas indústrias de fermentação. Estes estresses podem resultar numa redução ou restrição no crescimento e metabolismo das linhagens e afetar seriamente a indústria (Penninckx, 2000). 


\subsubsection{Superóxido dismutase}

A superóxido dismutase (SOD, EC 1.15.1.1) consiste num grupo de metaloenzimas que catalisam a formação de peróxido de hidrogênio $\left(\mathrm{H}_{2} \mathrm{O}_{2}\right)$ a partir de radicais superóxido $\left(\mathrm{O}_{2}^{-\bullet}\right)$, consumindo-os, e assim, livrando as células do risco de oxidação por esses radicais, como pode ser observado na seguinte reação:

$2 \mathrm{O}_{2}^{--}+2 \mathrm{H}^{+} \longrightarrow \mathrm{O}_{2}+\mathrm{H}_{2} \mathrm{O}_{2}$

As SODs são as únicas enzimas cujas atividades interferem nas concentrações de $\mathrm{O}_{2}^{-\bullet}$ e $\mathrm{H}_{2} \mathrm{O}_{2}$, os dois substratos da reação de Haber-Weiss que origina os radicais $\mathrm{OH}^{\bullet}$ e provavelmente por isso, as SODs representam o mecanismo de defesa central dos organismos vivos (Bowler et al., 1992 e Alscher et al., 1998).

Estas metaloenzimas multiméricas têm sido classificadas em três grupos de acordo com o componente metálico de seu sítio ativo: cobre/zinco ( $\mathrm{Cu} / \mathrm{Zn}$ ), manganês (Mn) ou ferro (Fe) (Scandalios, 1993; Mattson, 1998; Niyogi, 1999 e Mallick \& Mohn, 2000), sendo que a Cu/Zn-SODs são consideradas as mais abundantes em vegetais (Wingsle et al., 1991). As Cu/Zn-SODs e algumas MnSODs e Fe-SODs de procariotos são diméricas, enquanto as Mn-SODs das mitocôndrias e de algumas bactérias termófilas são tetraméricas (Scandalios, 1993).

De maneira geral, as Cu/Zn-SODs são encontradas no citosol e no estroma dos cloroplastos e são sensíveis à concentrações de $\mathrm{CN}^{-}$(radical cianeto) (Mallick \& Mohn, 2000). As Mn-SODs e Fe-SOD não são sensíveis ao $\mathrm{CN}^{-}$e têm sido encontradas geralmente na matriz mitocondrial de células 
eucarióticas e em células procarióticas, embora uma Mn-SOD associada à membrana tem sido observada nos cloroplastos de algumas plantas (Sehmer \& Dizengremel, 1998). A Fe-SOD foi observada em algumas famílias de plantas e está associada principalmente com os cloroplastos (Mallick \& Mohn, 2000).

Bowler et al. (1992) relataram em seus estudos de filogenia da SOD que a Mn-SOD e Fe-SOD são as mais antigas, indicando que provavelmente evoluíram antes da divergência entre procariotos e eucariotos, enquanto que a $\mathrm{Cu} / \mathrm{Zn}-\mathrm{SOD}$, mais recente, evoluiu independentemente em algum ponto no início da linhagem eucariótica.

\subsubsection{Catalase}

A catalase (CAT, EC.1.11.1.6.) é uma enzima tetramérica, que contém grupos heme e é encontrada em todos os organismos vivos. Devido à sua ampla distribuição e capacidade de degradar rapidamente o peróxido de hidrogênio, foi proposto por vários pesquisadores que a catalase desempenha um papel fundamental nos sistemas que capacitam os organismos a viverem em ambientes aeróbicos (Mallick \& Mohn, 2000; Verduyn et al., 1988). Sua reação pode ser observada na reação abaixo:

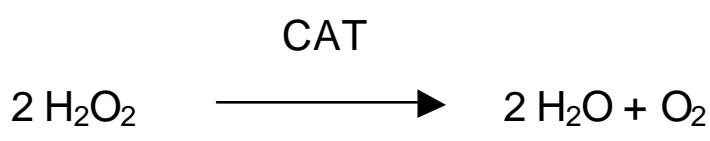

A catalase é a única entre as enzimas degradantes de $\mathrm{H}_{2} \mathrm{O}_{2}$ que não consome equivalentes redutores celulares e possui um mecanismo muito eficiente para remover o peróxido de hidrogênio, que são formados nas células sob condições de estresse (Mallick \& Mohn, 2000). Esta enzima se localiza 
numa organela denominada peroxissomo a qual é especializada em produzir e consumir $\mathrm{o}_{2} \mathrm{O}_{2}$ (Verduyn et al., 1988).

As evidências sugerem que a catalase utiliza mecanismo de dois estágios tanto nas reações peroxidativas como nas catalíticas. No primeiro estágio o ferro do grupo heme da catalase interage com $\circ \mathrm{H}_{2} \mathrm{O}_{2}$ para formar um peróxido de ferro rico em oxigênio. Este composto intermediário é denominado de componente I. A baixas concentrações de $\mathrm{H}_{2} \mathrm{O}_{2}\left(<10^{-6} \mathrm{~mol} / \mathrm{L}\right)$, o componente I pode ser reduzido por uma variedade de doadores de hidrogênio (por exemplo, etanol e ácido ascórbico). A elevadas concentrações de $\mathrm{H}_{2} \mathrm{O}_{2}, \mathrm{O}$ componente I reage com uma segunda molécula de $\mathrm{H}_{2} \mathrm{O}_{2}$ para produzir água e uma molécula de oxigênio (Scandalios, 1994).

Várias condições ambientais podem alterar a CAT, por exemplo, no procarioto simbionte autotrófico, Prochloron sp., a atividade da CAT foi diretamente proporcional à irradiação (Lesser e Stochaj, 1990). Por outro lado, a mudança na temperatura afetou da mesma forma a atividade da CAT na cianobactéria Synechocystis (Rady et al., 1994).

Culturas de células de algas submetidas a baixa temperatura apresentaram um aumento considerável na atividade de CAT. Entretanto, com a elevação da temperatura, a atividade foi inibida significativamente. Em relação à exposição ao cobre e radiação UV-B, foi observado um aumento expressivo na atividade da CAT na cianobactéria fixadora de $\mathrm{N}_{2}$, Anabaena doliolum e na alga verde Chlorella vulgaris, respectivamente (Mallick e Rai, 1999; Malanga et al, 1999).

No Aspergillus nidulans, duas isoenzimas de CAT foram identificadas. CAT $\mathrm{A}$, codificada pelo gene catA, cuja transcrição é induzida especificamente durante a esporulação e em resposta a diferentes tipos de estresse. E a CAT B, codificada pelo gene catB, a qual está presente no micélio (Calera et al., 2000).

A expressão da catB é induzida pelo $\mathrm{H}_{2} \mathrm{O}_{2}$ ou $\mathrm{H}_{2} \mathrm{O}_{2}{ }^{-}$, sem controle regulatório pós-transcricional. As enzimas CatA e CatB constituem portanto, 
mecanismos de defesa antioxidantes alternativos específicos para os diferentes estágios do ciclo de vida do A. nidulans (Calera et al., 2000).

Em plantas, as catalases concentram-se no citoplasma, principalmente nos peroxissomos de folhas e glioxissomos de tecidos que armazenam lipídios, com exceção da CAT-3 de milho e da CAT de algumas algas verdes que são mitocondriais, embora esta última ainda não tenha papel fisiológico totalmente compreendido (Skadsen et al., 1995; Frugoli et al., 1996 e Iwamoto et al., 1998).

\subsubsection{Glutationa redutase}

A glutationa reduzida (GSH), é um importante metabólito no combate à ROS especificamente $\left(\mathrm{O}_{2}{ }^{-}\right.$e $\left.\mathrm{H}_{2} \mathrm{O}_{2}\right)$ via ciclo Halliwell-Asada, onde a enzima chave é a Glutationa Redutase (GR) (Lea et al., 1998).

A enzima GR (NADPH: glutationa oxidada oxidorredutase, E.C.1.6.4.2.) (Vallejos, 1983) é uma enzima amplamente distribuída em procariotos e eucariotos, desde bactérias heterotróficas e fotossintetizantes até plantas e animais superiores (Creissen et al., 1994). A GR contém um grupo prostético flavina adenina dinucleotídeo (FAD) transferidor de elétrons que catalisa a redução dependente de NADPH da glutationa oxidada (GSSG) para glutationa reduzida (GSH) (Creissen et al., 1994 e Voet \& Voet, 1995), conforme a seguinte reação:

\section{GR}

GSSG

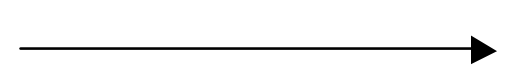

GSH

(glutationa oxidada)

(glutationa reduzida)

Foram realizados poucos trabalhos estudando a GR em microrganismos, sendo relatado um aumento na atividade desta enzima sob elevada irradiação 
(Lesser e Stochaj, 1990), deficiência de água (Smirnoff, 1993) e estresses promovidos por extremos de temperatura (Rady et al., 1994). No Penicillium chrysogenum foi observado um aumento significativo na GR na presença de peróxidos (Emri, et al. 1997). Em A. doliolum, entretanto, a exposição ao cobre promoveu um efeito negativo na atividade da GR (Mallick e Rai, 1999).

O gene que confere tolerância ao $\mathrm{Cd}$ na levedura Saccharomyces cerevisiae (YCF1) foi isolado e mostrourse que este catalisa seletivamente 0 transporte do bis(glutationato) de cádmio para o vacúolo, num mecanismo que contribui para a desintoxicação deste metal (Li, 1997). As leveduras Schizosaccharomyces pombe e Candida glabrata, quando expostas ao $\mathrm{Cd}$ sintetizam e excretam derivados do peptídeo GSH juntamente com íons de Cd, entre este derivados foram encontrados metalotioneínas. Nos mutantes deficientes em produzir a GSH houve uma perda na habilidade de excretar o $\mathrm{Cd}$ (Kistler et al., 1986 e Penninckx, 2000).

A importância da GR consiste em manter o equilíbrio GSH/GSSG na célula, pois a GSH é uma molécula que apresenta uma função essencial de manter as células no seu estado reduzido. Portanto, ela atua como um agente antioxidante, seja interagindo diretamente com as ROS, como indiretamente reduzindo peróxidos através da ação da glutationa peroxidase (Fufii, et al. 2000; Stephen \& Jamieson, 1996; Meister, 1983 e Stamler, 1994).

\subsubsection{Guaiacol peroxidase}

As peroxidases são hemeproteínas que catalisam a oxidação do substrato concomitantemente à redução do peróxido de hidrogênio. As peroxidases participam de vários processos metabólicos essenciais incluindo regulação do crescimento celular (Goldberg et al.,1986), lignificação (Grisebach, 1981), oxidação fenólica, defesa contra patógenos e proteção contra estresses (Tekchandani et al., 1998). 
Nas espécies vegetais e em particular no linho (Linum usitatissimum), a guaiacol peroxidase apresenta isoformas ácidas e básicas. $\mathrm{A}$ isoforma ácida está envolvida numa variedade de processos relacionada com a biossíntese da parede celular, incluindo a formação de lignina. A isoforma básica participa da regulação da degradação do AIA (ácido indol-acético) e da síntese de etileno (Fieldes \& Gerhardt, 1998).

Em experimentos in vitro, a guaiacol catalisa a oxidação dos doadores de hidrogênio devido à ausência de substrato específico, no entanto, in vivo esta enzima pode utilizar o ascorbato como substrato para suas reações. Neste caso, a desintoxicação pode se tornar a função principal de algumas isoformas (Fieldes \& Gerhardt, 1998). Como exemplos, podemos citar em plantas o aumento na atividade da guaiacol peroxidase na presença da radiação UV-B, constatado em Hibiscus rosa-sinensis e Beta vulgaris (Panagopoulos et al., 1989 e 1990). O aumento na atividade desta enzima pode ser devido àsíntese da mesma, bem como devido à supressão da atividade de um inibidor natural da guaiacol peroxidase (Tekchandani, 1998). Entretanto, na maioria dos organismos, as principais funções das peroxidases não foram bem esclarecidas. Supõe-se que o estudo das alterações provocadas pela indução de estresses fisiológicos poderia contribuir para a melhor compreensão da ação específica das isoformas da guaiacol peroxidase (Campa, 1991). 


\section{MATERIAIS E MÉTODOS}

\subsection{Material biológico}

Linhagem MSE - com as seguintes marcas genéticas: ${ } A_{3}, \operatorname{facA}_{303}$, gal $\mathrm{A}_{1}, y \mathrm{~A}_{1}$, pyro $\mathrm{A}_{4}, \mathrm{sB}_{3}$, nic $\mathrm{B}_{6}$ e ribo (McCully \& FORBES, 1965).

Esta linhagem é derivada do selvagem de $A$. nidulans, originário do Departamento de Genética da Universidade de Glasgow, Escócia. Foi cedida pelo Departamento de Genética da Universidade de Sheffiel, Inglaterra.

\subsection{Meios de cultura}

\subsubsection{Meio Completo}

Preparado de acordo com Pontecorvo et al. (1953) e modificado por Azevedo \& Costa (1973).

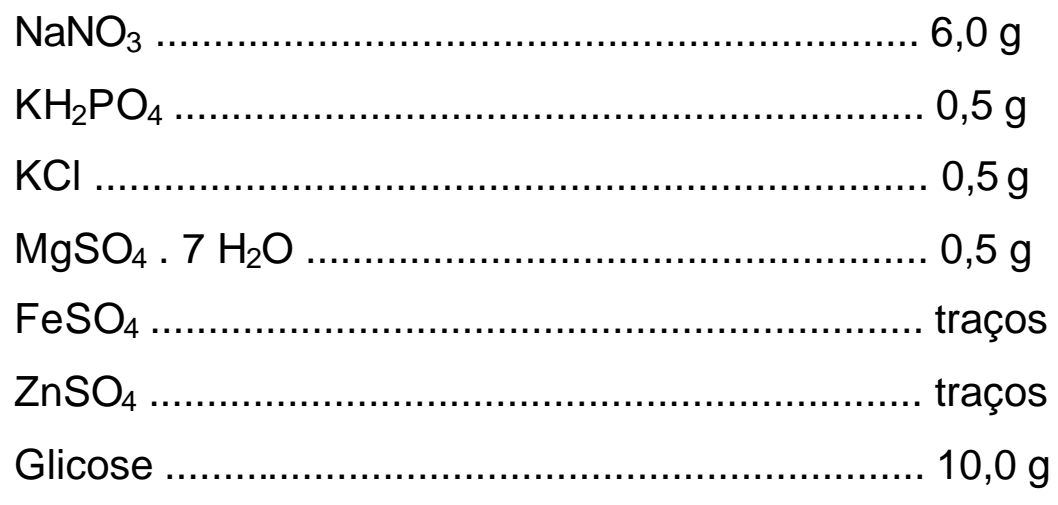




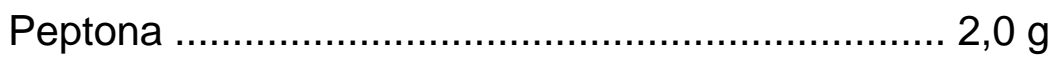

Caseína hidrolisada... ..................................... 1,5 g

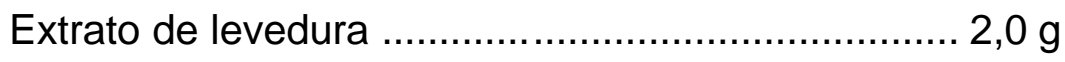

Solução de Vitaminas .................................... 1,0 mL

Ágar ........................................................... 20,0 g

Água destilada ....................................... 1000,0 mL

$\mathrm{O} \mathrm{pH}$ foi ajustado para $6,8 \mathrm{com} \mathrm{NaOH} 10 \%$ e o meio foi esterilizado em autoclave sob 1 atm por 20 minutos.

\subsubsection{Meio Completo líquido}

Preparado como descrito no item 3.2.1, sem adição de ágar.

\subsection{Soluções}

\subsubsection{Solução de vitaminas}

Ácido nicotínico.................................................... 10,0 mg

Ácido $\rho$-aminobenzóico .............................................. 1,0 mg

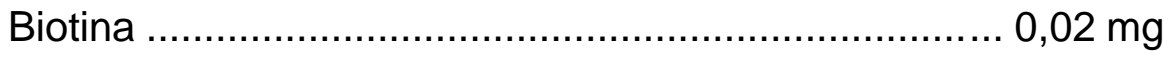

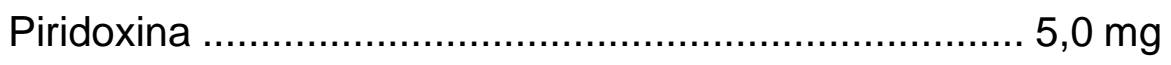

Riboflavina …............................................. 10,0 mg

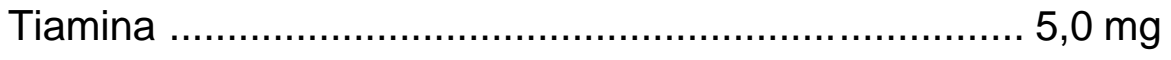

Água destilada ................................................ 10,0 mL 
As vitaminas foram adicionadas a água destilada, previamente esterilizada as solução assim conduzidas ao banho-maria por 15 minutos e conservadas em refrigerador, em frasco escuro, com clorofórmio.

\subsubsection{Solução de Tween 80}

Tween 80 $0,1 \mathrm{~mL}$

Água destilada $100,00 \mathrm{~mL}$

O tween foi dissolvido em água destilada e a solução obtida transferida para tubos de ensaio com 2,5 mL cada um. Foi esterilizado em autoclave sob 1 atm por 20 minutos.

\subsubsection{Solução Salina}

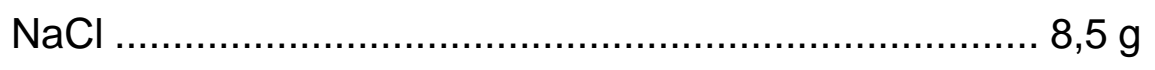

Água destilada .............................................. 1000,0 mL

Foi colocado o volume de $9,0 \mathrm{~mL}$ por frasco e foi esterilizado em autoclave sob $1 \mathrm{~atm}$ por 20 minutos.

\subsection{Experimento básico}

Obtenção de micélio para determinação de peso seco e ensaios enzimáticos.

Esporos do $A$. nidulans (MSE) foram obtidos a partir do inóculo de 3 pontos por placa de petri contendo meio completo sólido $(\mathrm{MC})$ e mantidos à 
$37^{\circ} \mathrm{C}$, por 4 dias. A concentração inicial dessa suspensão foi estimada com 0 emprego de câmara de Neubauer e ajustada para inocular $3 \times 10^{7}$ esporos $/ \mathrm{mL}$ em $100 \mathrm{~mL}$ de $\mathrm{MC}$ em frascos Erlenmeyers de $250 \mathrm{~mL}$. Tais recipientes foram dispostos em agitador rotatório à $37^{\circ} \mathrm{C}$ e $110 \mathrm{rpm}$ por períodos de tempo definidos, posteriormente o micélio foi separado do meio de cultura através de filtração àvácuo.

Foram realizados ensaios preliminares para se estabelecer os períodos de tempo e concentrações de $\mathrm{CdCl}_{2}$ mais adequados ao experimento básico de obtenção de micélio e ensaios enzimáticos. Empregando-se esses parâmetros foram realizados dois ensaios, com três repetições por tratamento, para o estudo da linhagem MSE do $A$. nidulans.

Um dos ensaios avaliou a massa do micélio obtido sob as condições de tratamento e o outro forneceu material para a realização das análises enzimáticas.

Para avaliação da massa seca do micélio, o primeiro ensaio, foram testados os efeitos das concentrações $0 ; 0,005 ; 0,010 ; 0,025$ e 0,050 mM de $\mathrm{CdCl}_{2}$ e dos tempos de exposição $6,9,12,24 \mathrm{~h}$, a partir de 12 horas de crescimento em MC líquido. Para avaliação da atividade enzimática o mesmo ensaio foi montado, o micélio obtido foi filtrado e congelado em nitrogênio líqüido, sendo armazenado em biofreezer a $-80^{\circ} \mathrm{C}$ até a realização da extração para os ensaios enzimáticos.

Após a caracterização do efeito do $\mathrm{Cd}$ na linhagem MSE, foram conduzidos experimentos envolvendo tanto essa linhagem quanto uma de Aspergillus sp. (CadG1) tolerante ao $\mathrm{Cd}$. Neste conjunto de ensaios, o período foi exposição ao $\mathrm{Cd}$ foi de 24 horas e as concentrações foram $0 ; 0,005 ; 0,010$; 0,025 e 0,050 mM de $\mathrm{CdCl}_{2}$, a partir de 12 horas de crescimento em MC líquido. 


\subsection{Extração das enzimas}

A extração enzimática foi feita a partir do micélio do Aspergillus sp. As células foram homogeneizadas em tampão fosfato de potássio $100 \mathrm{mM}, \mathrm{pH} 7,5$ (3 $\mathrm{g}: 1 \mathrm{~mL}$ ) contendo $1 \mathrm{mM}$ de EDTA, $3 \mathrm{mM}$ de DTT e 4\% $(\mathrm{p} / \mathrm{v})$ de PVPP. O homogeneizado foi centrifugado a $10.000 \mathrm{rpm}$ por $30 \mathrm{~min}$ a $4^{\circ} \mathrm{C}$, utilizando-se uma centrífuga Beckmam modelo J2-MC. O sobrenadante foi coletado, dividido em alíquotas e congelados a $-80^{\circ} \mathrm{C}$, sendo utilizado para os ensaios das atividades enzimáticas.

\subsection{Determinação de proteínas}

A concentração de proteína foi determinada em espectrofotômetro a 595nm como descrito por Bradford (1976), utilizando-se o kit da Bio-Rad e BSA como padrão.

\subsubsection{Gel de proteínas SDS-PAGE}

O gel de proteínas desnaturadas foi avaliado pelo método PAGE segundo Woodbury et al. (1971) e foi adicionado o desnaturante SDS. As amostras foram fervidas por 5 minutos e adicionadas no gel na quantidade de $0,1 \mathrm{mg}$ de proteínas de micélio. A concentração do gel principal foi de $8 \%$ de poliacrilamida com um gel de empilhamento contendo $4 \%$. Os tampões e géis de eletroforese foram preparados como descrito por Laemmli (1970). A eletroforese foi conduzida a $4^{\circ} \mathrm{C}$ em corrente constante de $15 \mathrm{~mA} /$ placa em um tempo médio de corrida de $3 \mathrm{~h}$. Os géis foram corados com a solução Comassie Blue por 10 horas e depois colocados em solução descorante por 5 
dias. A solução descorante é formada por $25 \mathrm{~mL}$ de ácido acético, $35 \mathrm{~mL}$ de metanol completando $500 \mathrm{~mL}$ de água destilada.

\subsubsection{Atividade da catalase}

A atividade de CAT foi avaliada pelo método PAGE não-desnaturante, segundo Woodbury et al. (1971). O micélio teve suas proteínas separadas em PAGE não-desnaturante numa concentração de $8 \%$ de poliacrilamida com um gel de empilhamento contendo $4 \%$. Os tampões e géis de eletroforese foram preparados como descrito por Laemmli (1970).

A eletroforese foi conduzida a $4^{\circ} \mathrm{C}$ em corrente constante de 15 $\mathrm{mA} /$ placa em um tempo médio de corrida de 6h. Foram aplicados aos géis amostras de padrão de CAT de fígado bovino (2 unidades) e 0,2 mg de proteína do micélio. A revelação foi feita incubando-se o gel por 10 minutos em solução $0,003 \%$ de $\mathrm{H}_{2} \mathrm{O}_{2}$ e, posteriormente, em uma solução $1 \%(\mathrm{p} / \mathrm{v})$ de $\mathrm{FeCl}_{3}$ e $1 \%(p / v)$ de $\mathrm{K}_{3} \mathrm{Fe}\left(\mathrm{CN}_{6}\right) 1 \%(\mathrm{p} / \mathrm{v})$, por 10 minutos.

\subsubsection{Atividade da superóxido dismutase}

A atividade de SOD e suas isoformas foram determinadas em PAGE não-desnaturante e foram conduzida nas mesmas condições como descrito para CAT (3.6.2).

Foram aplicados aos géis $0,2 \mathrm{mg}$ de proteína de extrato de micélio de fungo. O tempo de corrida foi de aproximadamente 4 horas, os géis foram lavados em água destilada e incubados no escuro por 30 minutos a temperatura ambiente, em uma solução contendo $100 \mathrm{mM}$ de tampão fosfato de potássio (pH 7,8), 1mM de EDTA, 0,05 mM de riboflavina, $0,1 \mathrm{mM}$ de NBT e $0,3 \%(\mathrm{v} / \mathrm{v})$ 
de TEMED. Em alguns géis foram aplicados amostras de padrão de SOD de fígado de bovino (2 unidades).

\subsubsection{Determinação das isoenzimas de SOD}

Para a determinação das isoformas de SOD, o micélio foi submetido a PAGE não-desnaturante em mini-gel (8\%). A eletroforese foi conduzida a $4^{\circ} \mathrm{C}$ com uma corrente constante de $15 \mathrm{~mA} /$ placa por $6 \mathrm{~h}$.

Ao final da eletroforese, o gel foi dividido verticalmente em três partes iguais. A primeira parte foi revelada para atividade de SOD como acima (3.6.3), a segunda e a terceira parte foram incubadas por 20 minutos em $100 \mathrm{mM}$ de tampão fosfato de potássio $(\mathrm{pH} 7,8)$ contendo $2 \mathrm{mM} \mathrm{KCN}$ e $100 \mathrm{mM}$ de tampão fosfato de potássio $(\mathrm{pH} 7,8)$ contendo $5 \mathrm{mM}$ de $\mathrm{H}_{2} \mathrm{O}_{2}$, respectivamente. Após este período, ambas as partes foram lavadas e reveladas para atividade de SOD. O pré-tratamento dos géis em $\mathrm{H}_{2} \mathrm{O}_{2}$ e $\mathrm{KCN}$ antes da revelação de SOD permitiu a classificação das isoenzimas da SOD em Cu/Zn-SOD, Fe-SOD ou Mn-SOD. Mn-SOD é resistente à ambos inibidores, Fe-SOD é resistente ao $\mathrm{KCN}$ e inibida por $\mathrm{H}_{2} \mathrm{O}_{2}$ e $\mathrm{Cu} / \mathrm{Zn}-\mathrm{SOD}$ é inibida por ambas as substâncias (Azevedo et al., 1998).

\subsubsection{Atividade da glutationa redutase}

A atividade de GR foi determinada pelo método espectrofotométrico, conforme descrito por Azevedo et al. (1998).

A atividade enzimática foi determinada colorimetricamente a $30^{\circ} \mathrm{C}$ em uma solução consistindo de $1 \mathrm{~mL}$ de tampão fosfato de potássio $100 \mathrm{mM}(\mathrm{pH}$ $7,5)$ contendo $1 \mathrm{mM}$ de DTNB, $1 \mathrm{mM}$ de GSSG e 0,1 mM de NADPH. A reação foi iniciada com a adição de $50 \mu \mathrm{L}$ de extrato vegetal. A taxa de redução da 
GSSG foi monitorada pelo aumento, a cada segundo, na absorbância a 412 nm por 1 minuto. Os valores de atividade foram expressos em $\mu \mathrm{mol} / \mathrm{min} / \mathrm{mg}$ proteína.

\subsubsection{Atividade de guaiacol peroxidase}

A atividade de guaiacol peroxidase foi determinada em PAGE nãodesnaturante e foi conduzida nas mesmas condições como descrito para CAT (3.6.2).

Foram aplicados aos géis $100 \mu \mathrm{g}$ de proteína de amostras de folha e raiz de milho e de micélio das linhagens MSE e CadG1. Após um tempo de $4 \mathrm{~h}$ para eletroforese, os géis foram lavados em água destilada e incubados à temperatura ambiente, em uma solução contendo $100 \mathrm{~mL}$ de tampão fosfato de sódio (50 mM, pH 6,0), $250 \mu \mathrm{L}$ de guaiacol e $50 \mu \mathrm{l} \mathrm{H}_{2} \mathrm{O}_{2}$.

Após o aparecimento das bandas a solução foi retirada e os géis mergulhados em água destilada.

\subsection{Análise estatística}

Cada experimento foi realizado com três repetições e os dados quantitativos foram estatisticamente analisados através da análise de variância no programa SAS. 


\section{RESULTADOS}

Foram realizadas analises preliminares para determinar os períodos de tempo e as concentrações mais adequadas para estudar o comportamento enzimático da linhagem MSE do fungo Aspergillus nidulans na presença do $\mathrm{Cd}$. O critério utilizado para a determinação das concentrações desse metal foi a estabilização do peso seco do micélio, o qual foi atingido com $0,025 \mathrm{mM}$ de $\mathrm{CdCl}_{2}$. Para a determinação dos períodos de tempo de exposição, foram escolhidos os que melhor indicassem as transformações ocorridas em função da presença do metal. Na Figura 1 pode se observar que houve um crescimento gradativo do fungo no decorrer do tempo. Apesar disto, as concentrações de 0,025 e 0,050 mM representaram um efeito tóxico, inibitório, de padrão semelhante nos diferentes períodos estudados (6, 9, 12 e 24h). Ou seja, mesmo com maior tempo de crescimento, o fungo não apresentou aumento de peso seco nas concentrações de 0,025 e 0,050 mM em relação ao controle. Não se pode afirmar que estas concentrações foram letais para o fungo, pois foram inoculados micélios provenientes destes tratamento, os quais apresentaram crescimento subseqüente. É possível entretanto, que tal crescimento deva-se à germinação de esporos que estavam em estado de latência, uma vez que, sendo os esporos estruturas de resistência, estes seriam capazes de resistir mais tempo que o micélio, sob condições adversas.

Para uma análise mais completa dos mecanismos de defesa deste fungo na presença do metal pesado cádmio prosseguiu-se com o estudo das enzimas antioxidativas. 
Cabe acrescentar, ainda quanto a Figura 1, que em todos os períodos de tempo (6, 9, 12 e 24h) houve um acréscimo de peso seco na concentração de $0,005 \mathrm{mM}$ nas condições estudadas $\left(3 \times 10^{7}\right.$ esporos $/ \mathrm{mL}$ em $100 \mathrm{~mL}$ em meio completo). Embora não seja um aumento significativo, sua importância decorre de ter se apresentado em todos os períodos de tempo analisados. Após a concentração de $0,005 \mathrm{mM}$, houve um decréscimo gradativo do peso seco nas concentrações de 0,010 e 0,025 mM, mostrando-se estável após esta concentração.

A Figura 1 mostra, ainda, os frascos de Erlenmeyer de $250 \mathrm{~mL}$ com esporos submetidos ao período de 24 horas nas concentrações estudadas (0; 0,$005 ; 0,010 ; 0,025$ e 0,050 mM). Pode-se notar claramente um aumento do número de esporos germinados na concentração de $0,005 \mathrm{mM}$, embora estes apresentem um volume menor, provavelmente decorrente do espaço limitante. Nota-se também, uma significativa redução da esporulação e do crescimento nas concentrações de 0,025 e 0,050 mM.

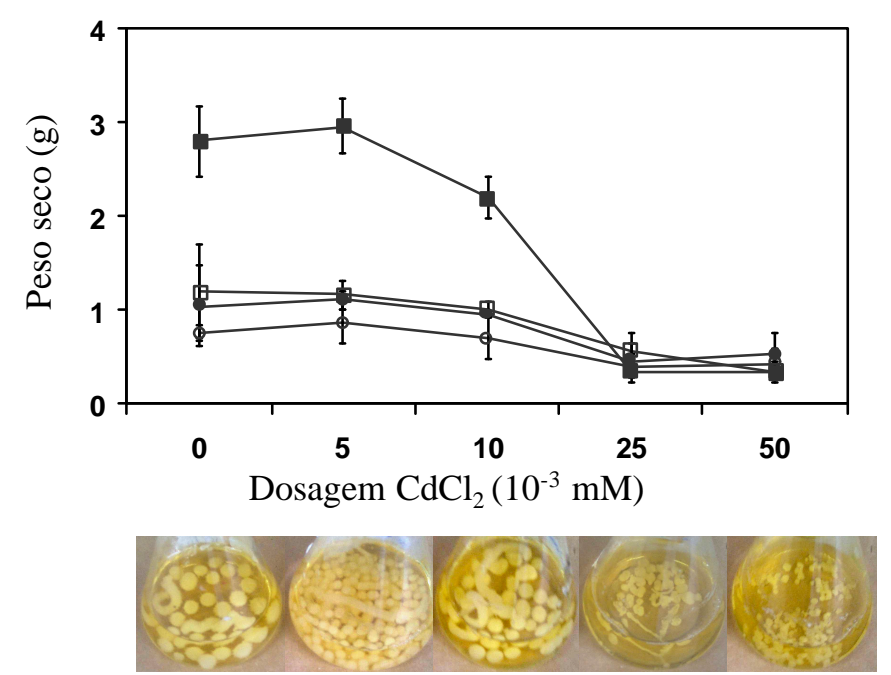

Figura 1 - Efeito das dosagens $0 ; 0,005 ; 0,010 ; 0,025$ e 0,050 mM de cádmio no peso seco do micélio da linhagem MSE em diferentes períodos de tempo, onde: O 6 horas, $\lambda 9$ horas, 12 horas e $v 24$ horas. $E$ respectivo crescimento nos frascos de Erlenmeyer para o período de 24 horas nas mesmas dosagens. 
A análise estatística, Tabela 1, mostra que as concentrações (Conc), os períodos de tempo (Horas) e a interação entre estes fatores apresentaram pelo menos um valor diferindo da média ao nível de significância de 1\%. A Tabela 1.1 mostra a mesma análise de variância fixando-se a concentração, desta forma é possível observar que as concentrações iniciais $(0,0,005$ e 0,010) apresentaram pelo menos um valor diferindo da média, trata-se do período de 24 horas o qual apresentou valores muito acima da média. As concentrações finais $(0,025$ e 0,050$)$ não apresentaram diferença significativa, ou seja, os diferentes períodos de tempo apresentaram valores de peso seco próximos da média para cada uma destas concentrações. Na Tabela 1.2 fixourse o período de tempo e variou-se as concentrações para cada hora. Pode-se observar que os período de 6 e 9 horas não apresentaram diferença significativa entre as diferentes concentrações de $\mathrm{Cd}$ administradas. O período de 12 horas apresentou uma diferença significativa ao nível de $5 \%$ e no período de 24 horas a diferença foi menor que $1 \%$. Estes dados mostram que apesar da dosagem de 0,025 e 0,050 mM de cádmio terem se mostrado tóxicas, o tempo de exposição é fundamental para que seja evidenciada sua toxicidade. O tempo de exposição ao cádmio por 24 horas apresentou o resultado mais claro, em relação à avaliação do peso seco, por ter permitido um crescimento adequado para o controle, o que pode evidenciar a diferença para as demais concentrações. 
Tabela 1. Análise de variância dos dados provenientes do peso seco do micélio da linhagem MSE - dados transformados segundo a expressão $y=(x+1)^{0,5}$.

\begin{tabular}{|c|c|c|c|c|c|}
\hline FV & GL & $S Q$ & QM & $\mathrm{F}$ & $\operatorname{Pr}>\mathrm{F}$ \\
\hline Bloco & 1 & 0,0002 & 0,0002 & 0,13 & 0,7249 \\
\hline Horas & 3 & 0,0771 & 0,0257 & **21,56 & 0,0001 \\
\hline Conc & 4 & 0,1134 & 0,0284 & ${ }^{* *} 23,78$ & 0,0001 \\
\hline Horas ${ }^{*}$ Conc & 12 & 0,0679 & 0,0057 & ${ }^{* *} 4,74$ & 0,0013 \\
\hline Resíduo & 19 & 0,0227 & 0,0012 & & \\
\hline TOTAL & 39 & 0,2813 & & & \\
\hline
\end{tabular}

${ }^{*} 5$ \% de significância; ** $1 \%$ de significância; $C V=3,09 \%$

Tabela 1.1. Análise de variância fixando o fator concentração.

\begin{tabular}{lrcccc}
\hline \multicolumn{1}{c}{ FV } & GL & SQ & QM & F & Pr $>F$ \\
\hline Bloco & 1 & 0,0002 & 0,0002 & & \\
Conc & 4 & 0,1134 & 0,0284 & & \\
Horas (0) & 3 & 0,0545 & 0,0182 & ${ }^{* *} 15,24$ & 0,0001 \\
Horas $(0,005)$ & 3 & 0,0584 & 0,0195 & ${ }^{* *} 16,33$ & 0,0001 \\
Horas $(0,010)$ & 3 & 0,0307 & 0,0102 & $* * 8,59$ & 0,0008 \\
Horas $(0,025)$ & 3 & 0,0007 & 0,0002 & 0,18 & 0,9066 \\
Horas (0,050) & 3 & 0,0007 & 0,0002 & 0,19 & 0,9021 \\
Resíduo & 19 & 0,0227 & 0,0012 & & \\
TOTAL & 39 & 0,2813 & & & \\
\hline
\end{tabular}


Tabela 1.2 Análise de variância fixando o fator hora.

\begin{tabular}{|c|c|c|c|c|c|}
\hline FV & GL & $S Q$ & QM & $\mathrm{F}$ & $\mathrm{Pr}>\mathrm{F}$ \\
\hline Bloco & 1 & 0,0002 & 0,0002 & & \\
\hline Horas & 3 & 0,0771 & 0,0257 & & \\
\hline Conc (6) & 4 & 0,0045 & 0,0011 & 0,94 & 0,4613 \\
\hline Conc (9) & 4 & 0,0096 & 0,0024 & 2,01 & 0,1336 \\
\hline Conc (12) & 4 & 0,0150 & 0,0038 & ${ }^{*} 3,15$ & 0,0383 \\
\hline Conc (24) & 4 & 0,1522 & 0,0381 & **31,91 & 0,0001 \\
\hline Resíduo & 19 & 0,0227 & 0,0012 & & \\
\hline TOTAL & 39 & 0,2813 & & & \\
\hline
\end{tabular}

O Figura 2 mostra a quantidade de proteínas totais nos períodos e concentrações estudados. Os períodos de 6 e 9 horas não apresentaram uma alteração significativa na quantidade total de proteínas, nas concentrações analisadas (Tabela 2.2). Os períodos de 12 e 24 horas apresentaram uma diferença significativa na quantidade total de proteínas, para a concentração de $0,050 \mathrm{mM}$ (Tabelas 2.1 e 2.2.)

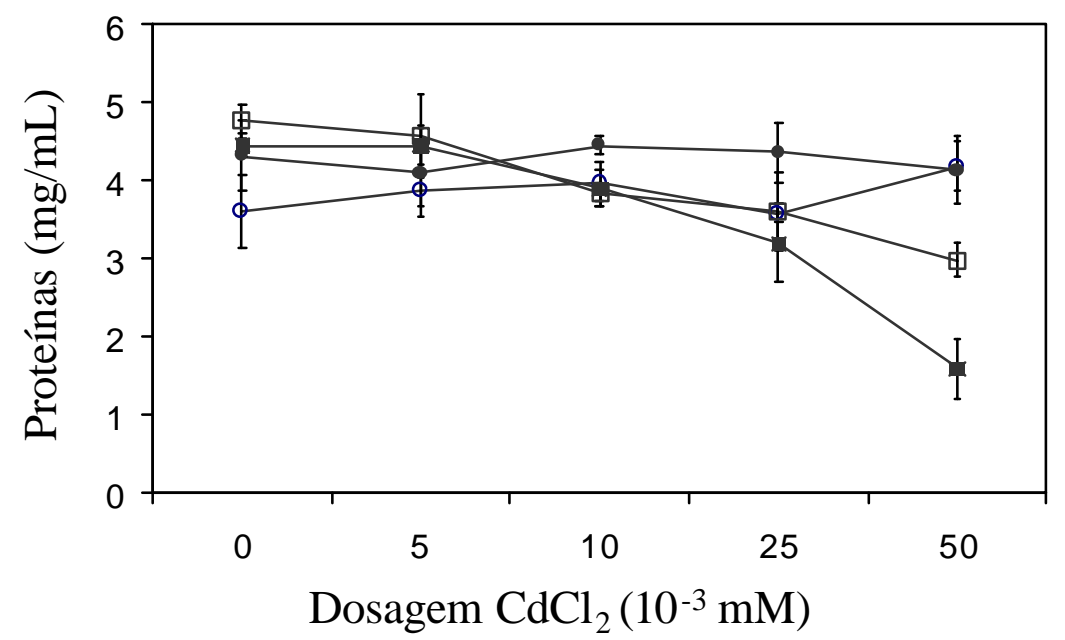

Figura 2 - Efeito das dosagens de $(0 ; 0,005 ; 0,010 ; 0,025$ e 0,050 mM) de cádmio nas proteínas totais do micélio da linhagem MSE em diferentes períodos de tempo, onde: 06 horas, $\lambda 9$ horas, 12 horas e $\vee 24$ horas. 
Tabela 2. Análise de variância dos dados provenientes das proteínas totais do micélio da linhagem MSE - dados não transformados.

\begin{tabular}{lrllrl}
\hline \multicolumn{1}{c}{ FV } & GL & \multicolumn{1}{c}{ SQ } & QM & \multicolumn{1}{c}{$\mathrm{F}$} & \multicolumn{1}{c}{$\operatorname{Pr}>\mathrm{F}$} \\
\hline Bloco & 1 & 0,4995 & 0,4995 & 2,13 & 0,1607 \\
Horas & 3 & 2,9236 & 0,9745 & ${ }^{*} 4,16$ & 0,0201 \\
Conc & 4 & 6,3356 & 1,5839 & ${ }^{* *} 6,76$ & 0,0015 \\
Horas*Conc & 12 & 9,9116 & 0,8260 & ${ }^{* *} 3,52$ & 0,0071 \\
Resíduo & 19 & 4,4545 & 0,2344 & & \\
TOTAL & 39 & 24,1248 & & & \\
\hline
\end{tabular}

* 5 \% de significância; ** $1 \%$ de significância; CV=12,42\%

Tabela 2.1. Análise de variância fixando o fator concentração.

\begin{tabular}{|c|c|c|c|c|c|}
\hline FV & GL & $S Q$ & QM & $\mathrm{F}$ & $\operatorname{Pr}>F$ \\
\hline Bloco & 1 & 0,4995 & 0,4995 & & \\
\hline Conc & 4 & 6,3356 & 1,5839 & & \\
\hline Horas(0) & 3 & 1,4428 & 0,4809 & 2,05 & 0,1407 \\
\hline Horas $(0,005)$ & 3 & 0,6236 & 0,2079 & 0,89 & 0,4658 \\
\hline Horas $(0,010)$ & 3 & 0,4740 & 0,1580 & 0,67 & 0,5786 \\
\hline Horas $(0,025)$ & 3 & 1,4143 & 0,4714 & 2,01 & 0,1466 \\
\hline Horas $(0,050)$ & 3 & 8,8805 & 2,9602 & $* * 12,63$ & 0,0001 \\
\hline Resíduo & 19 & 4,4545 & 0,2344 & & \\
\hline TOTAL & 39 & 24,1248 & & & \\
\hline
\end{tabular}


Tabela 2.2. Análise de variância fixando o fator horas.

\begin{tabular}{lrrlrr}
\hline \multicolumn{1}{c}{ FV } & GL & \multicolumn{1}{c}{ SQ } & QM & \multicolumn{1}{c}{$F$} & Pr $>$ F \\
\hline Bloco & 1 & 0,4995 & 0,4995 & & \\
Horas & 3 & 2,9236 & 0,9745 & & \\
Conc(6) & 4 & 0,5052 & 0,1263 & 0,54 & 0,7091 \\
Conc(9) & 4 & 0,1805 & 0,0451 & 0,19 & 0,9393 \\
Conc(12) & 4 & 4,2292 & 1,0573 & ${ }^{* *} 4,51$ & 0,0099 \\
Conc(24) & 4 & 11,3322 & 2,8331 & $* * 12,08$ & 0,0001 \\
Resíduo & 19 & 4,4545 & 0,2344 & & \\
TOTAL & 39 & 24,1248 & & & \\
\hline
\end{tabular}

Em concordância com o Figura 2, a Figura 3 mostra dois géis de SDS PAGE, nos períodos de 12 e 24 horas nas concentrações estudadas. Para o período de $12 \mathrm{~h}$, a concentração de $0,050 \mathrm{mM}$ mostrou um decréscimo de proteínas totais. O mesmo pode ser observado para o período de 24 horas, no qual o decréscimo foi mais significativo comparando-se com o controle.
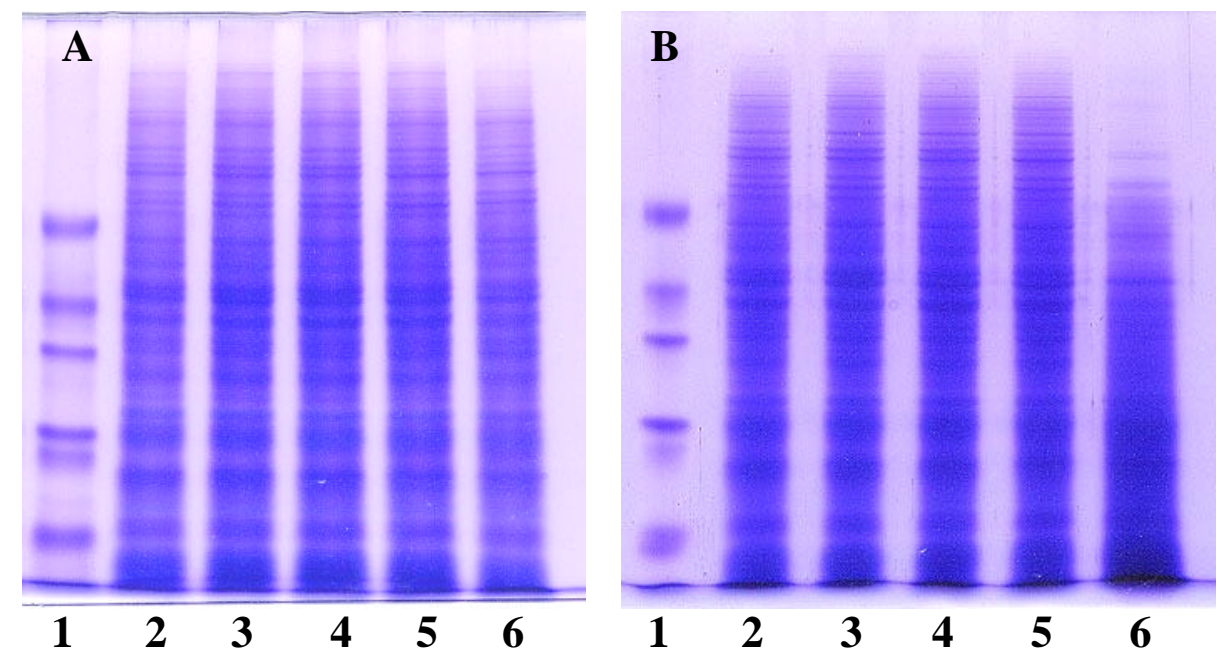

Figura 3 - Gel SDS - PAGE, onde A e B representam 12 e 24 horas de exposição, respectivamente: 1 , é o padrão de peso molecular; $2,3,4,5$ e 6 , representam as concentrações de 0; 0,005; 0,010;0,025 e 0,050 mM de $\mathrm{CdCl}_{2}$. 
A primeira enzima analisada foi a SOD. Conduzindo-se um estudo para caracterizar as isoformas desta enzima constatou-se que a linhagem MSE apresentou três isoformas de Mn-SOD quando uma quantidade de $1 \mathrm{~mL}$ foi adicionada na canaleta no mini-gel, na condição controle (sem exposição ao Cd). Quando esta enzima foi analisada nas diferentes condições deste experimento, a quantidade administrada ao gel permitiu a visualização de 2 isoformas (II e III, Figura 4), as quais corresponderam a quase toda a resposta desta enzima na linhagem MSE.

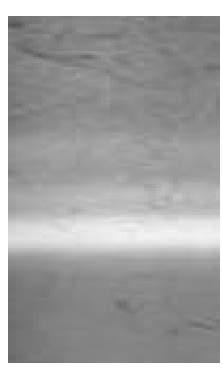

1

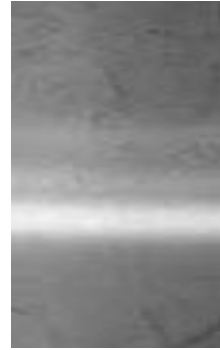

2

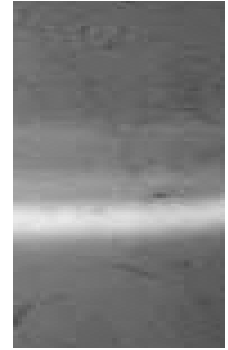

3

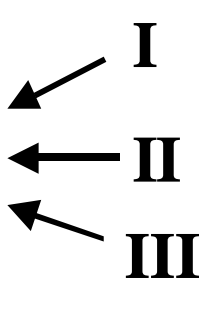

III

Figura 4 - Caracterização das isoenzimas da SOD, onde: 1, 2 e 3 representam os tratamentos normal, $\mathrm{KCN}$ e $\mathrm{H}_{2} \mathrm{O}_{2}$, respectivamente, os números romanos indicam as isoformas.

Nas condições do experimento, o período de 6 horas apresentou duas isoformas (II e III, Figura 5) as quais não sofrem alteração com o aumento das concentrações de cádmio. No período de 9 horas, houve uma aumento de atividade, principalmente na isoforma II, na concentração de $0,005 \mathrm{mM}$, e um novo aumento na concentração de $0,025 \mathrm{mM}$, ainda relevante na concentração seguinte $(0,05 \mathrm{mM})$. Os períodos de 12 e 24 horas apresentaram um decréscimo na atividade, com relação ao controle (sem exposição ao $\mathrm{Cd}$ ) nas dosagens de 0,005 e 0,01 mM, caracterizando posteriormente, uma tendência de aumento de atividade com o aumento das concentrações. Embora estes períodos tenham apresentado resultados semelhantes, a atividade com 12 horas foi mais 
significativa que no período de 24. Ou seja, no período de 24 horas a resposta da linhagem MSE em relação à atividade da enzima SOD foi menor que nos demais períodos. Aparentemente o pico de atividade da SOD neste fungo, nas condições estudadas ocorreu nos períodos de 9 e 12 horas, e nas concentrações de 0,025 e $0,050 \mathrm{mM}$.

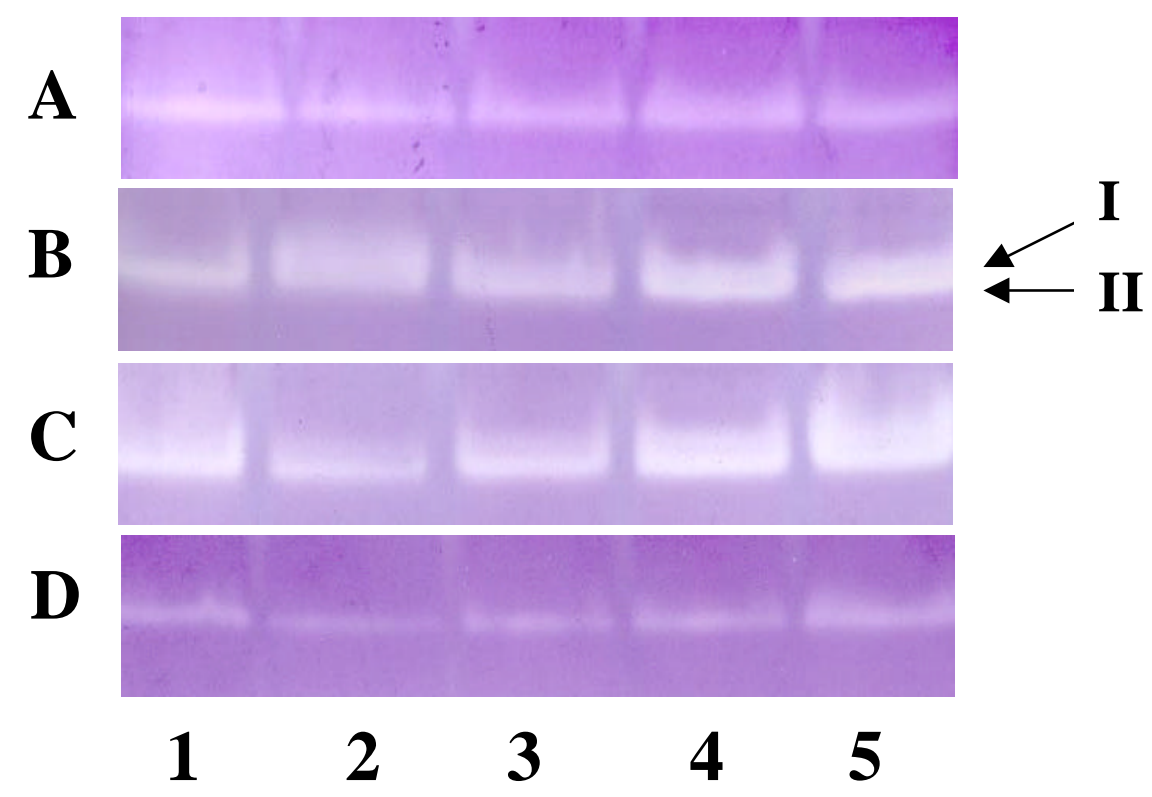

Figura 5 - Gel de atividade da SOD, onde A, B, C e D representam os períodos de exposição de 6, 9, 12 e 24 horas, respectivamente: 1, 2, 3, 4 e 5, representam as concentrações de 0; 0,005; 0,010; 0,025 e 0,050 mM de $\mathrm{CdCl}_{2}$.

A linhagem MSE apresentou três isoformas da enzima CAT nas condições estudadas, sendo duas isoformas com respostas mais expressivas (I e III, Figura 6). No período de 6 horas, assim como na SOD, praticamente não houve alteração na atividade enzimática, decorrente do aumento de dosagens. O período de 9 horas apresentou uma resposta na isoforma I na concentração de 0,050 mM. Nos períodos de 12 e 24 horas as respostas apresentaram uma tendência gradativa de aumento na atividade desta enzima, sendo mais intensa na concentração de $0,050 \mathrm{mM}$ e na isoforma I. Na isoforma III o aumento na 
atividade ocorreu abruptamente na concentração de $0,050 \mathrm{mM}$. A resposta na isoforma I, no período de 24 horas, foi expressiva, como se observa na figura $5 \mathrm{D}$.

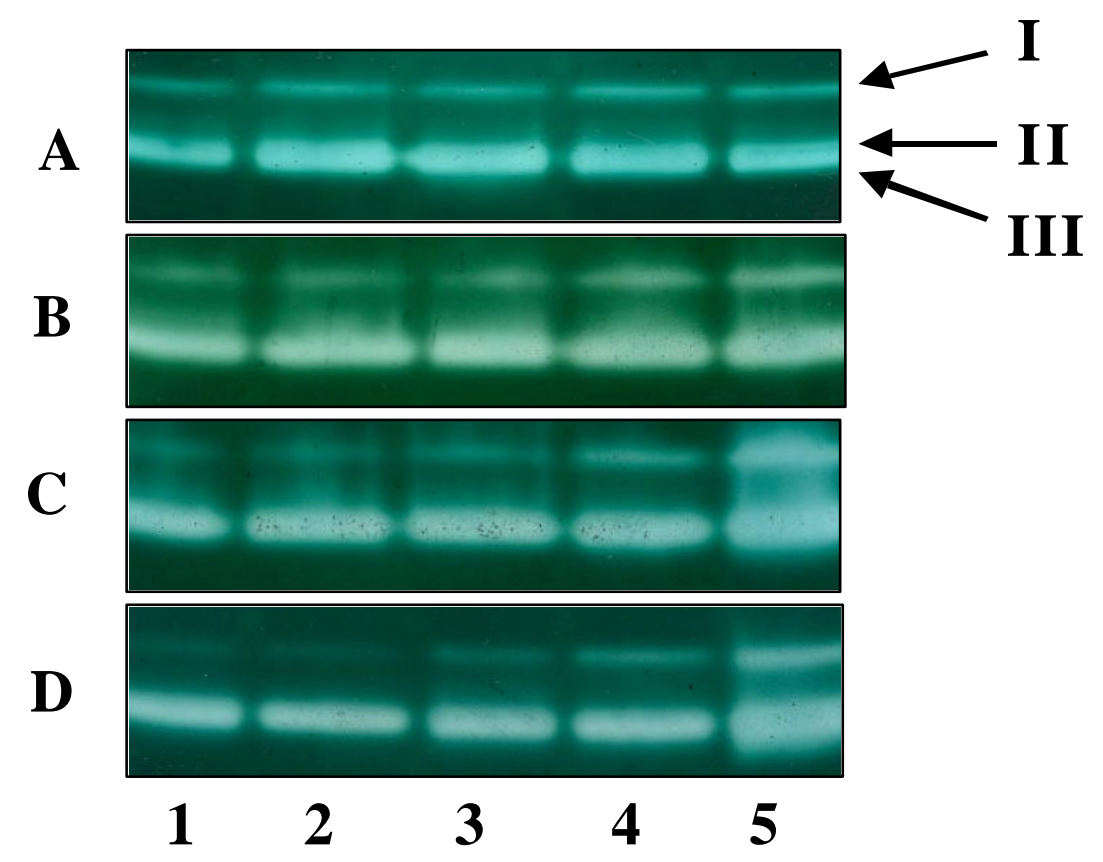

Figura 6 - Gel de atividade de CAT, onde A, B, C e D representam os períodos de exposição de 6, 9, 12 e 24 horas, respectivamente: 1, 2, 3, 4 e 5, representam as concentrações de 0; 0,005; 0,010; 0,025 e 0,050 mM de $\mathrm{CdCl}_{2}$.

Nas condições estudadas, a linhagem MSE do fungo $A$. nidulans não apresentou atividade da enzima guaiacol peroxidase como pode ser observado na Figura 7. Os números 1 e 2 indicam a presença da enzima em raízes e folhas de milho, respectivamente; os números 3 e 4 mostram ausência de atividade na linhagem MSE, sendo 3 o controle após 24 horas e 4 o mesmo período com $0,050 \mathrm{mM}$ de $\mathrm{Cd} \mathrm{Cl}_{2}$. A raiz de milho apresentou 7 isoformas da enzima e a folha 3 isoformas. 


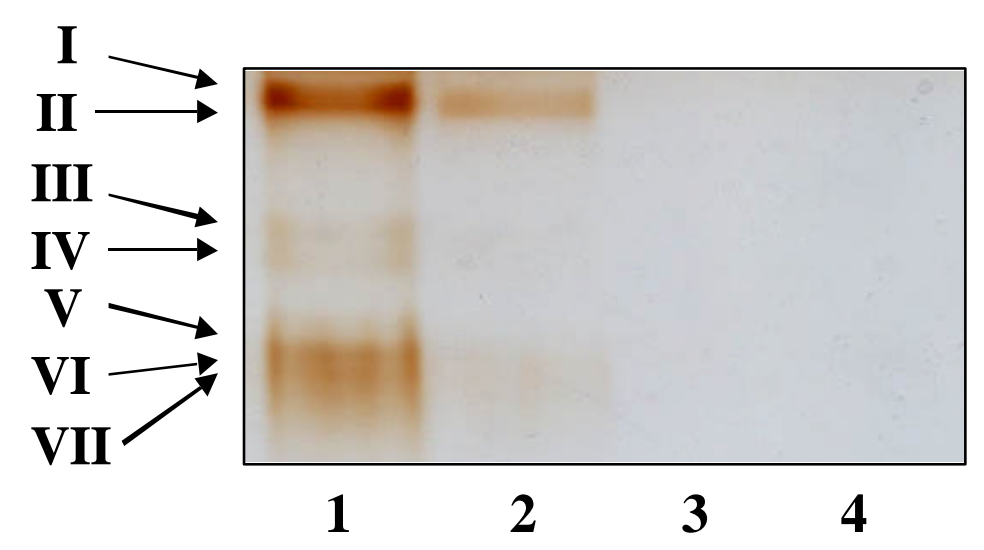

Figura 7 - Atividade da guaiacol peroxidase, onde: (1) raiz de milho, (2) folha de milho, (3) 24 horas e $0 \mathrm{Cd}$, e (4) 24 horas e 0,050 mM de Cd.

A linhagem MSE apresentou ainda, um aumento significativo da atividade enzimática da GR na presença do Cd (Figura 8). Constatourse um aumento médio de 2,7 vezes na presença de 0,050 mM em relação ao controle. Conforme se observa na análise de variância (Tabela 3), houve diferença significativa nos fatores períodos de tempo (horas), concentrações (conc) e na interação entre os mesmos. Fixando-se a concentração e analisando-se as atividades de GR nos diferentes períodos de tempo (Tabela 3.1), pode-se observar que não houve alteração na atividade desta enzima no controle e nas concentrações de 0,$005 ; 0,010$ e 0,025 mM, mantendo-se esse mesmo padrão nos diferentes períodos de exposição ao $\mathrm{Cd}$. Constatourse diferença significativa apenas na concentração $0,050 \mathrm{mM}$. A análise de variância efetuada com os períodos fixos (Horas) e variando-se as concentrações (Tabela 3.2), mostrou que os períodos de 6 e 9 horas apresentaram diferença significativa ao nível de $5 \%$ e os períodos de 12 e 24 horas ao nível de 1\%. Observando-se conjuntamente os dados das duas tabelas (3.1 e 3.2), podemos concluir que estas significâncias se devem à concentração de 0,050 mM de cádmio, o que mostra que esta concentração estimula uma resposta importante da GR para esta linhagem, nos períodos de tempo estudados. 


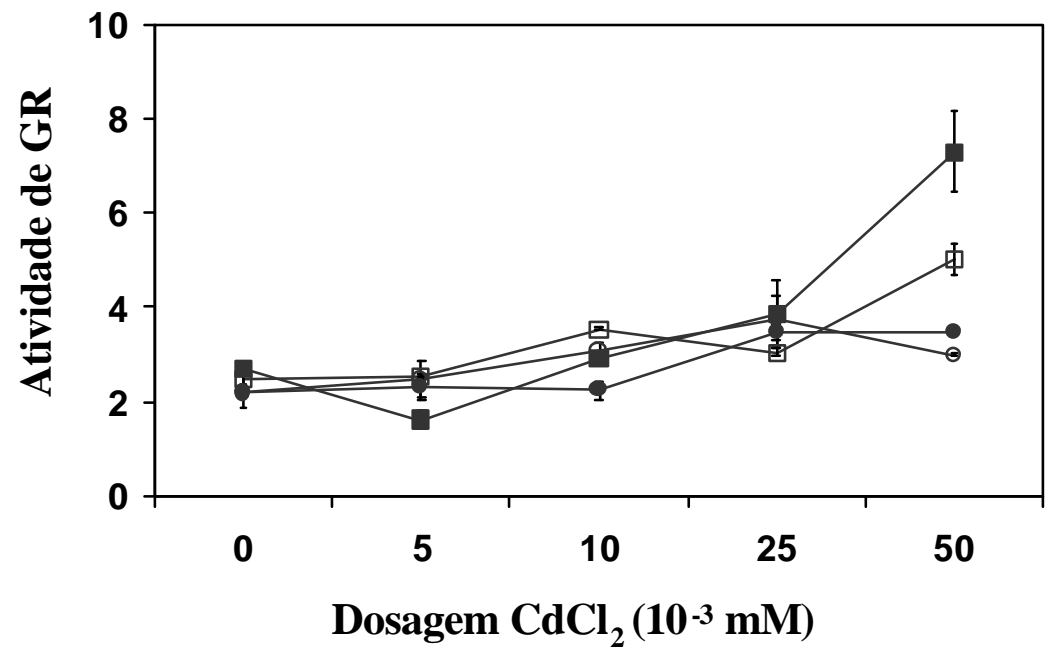

Figura 8 - Efeito das dosagens de (0; 0,005; 0,010; 0,025 e 0,050 mM) de cádmio na atividade de GR do micélio da linhagem MSE em diferentes períodos de tempo, onde: $O 6$ horas, $\lambda 9$ horas, 12 horas e $v 24$ horas.

Tabela 3. Análise de variância dos dados provenientes da atividade de GR do micélio da linhagem MSE - dados transformados segundo a expressão $\mathrm{y}=(\mathrm{x})^{0,5}$.

\begin{tabular}{lrllrl}
\hline \multicolumn{1}{c}{ FV } & GL & SQ & QM & \multicolumn{1}{c}{$F$} & $\operatorname{Pr}>\mathrm{F}$ \\
\hline Bloco & 1 & 0,0006 & 0,0006 & 0,03 & 0,8617 \\
Horas & 3 & 0,2813 & 0,0938 & ${ }^{*} 4,57$ & 0,0143 \\
Conc & 4 & 2,1811 & 0,5453 & ${ }^{* *} 26,56$ & 0,0001 \\
Horas ${ }^{*}$ Conc & 12 & 1,1932 & 0,0994 & ${ }^{* *} 4,84$ & 0,0012 \\
Resíduo & 19 & 0,3901 & 0,0205 & & \\
TOTAL & 39 & 4,0464 & & & \\
\hline
\end{tabular}

* 5 \% de significância; ${ }^{* *} 1 \%$ de significância; $C V=8,19 \%$ 
Tabela 3.1. Análise de variância fixando o fator concentração.

\begin{tabular}{|c|c|c|c|c|c|}
\hline FV & GL & SQ & QM & $\mathrm{F}$ & $\operatorname{Pr}>\mathrm{F}$ \\
\hline Bloco & 1 & 0,0006 & 0,0006 & & \\
\hline Conc & 4 & 2,1811 & 0,5453 & & \\
\hline Horas(0) & 3 & 0,0408 & 0,0136 & 0,66 & 0,5849 \\
\hline Horas $(0,005)$ & 3 & 0,1277 & 0,0426 & 2,07 & 0,1377 \\
\hline Horas $(0,010)$ & 3 & 0,1535 & 0,0512 & 2,49 & 0,0911 \\
\hline Horas $(0,025)$ & 3 & 0,0518 & 0,0173 & 0,84 & 0,4886 \\
\hline Horas $(0,050)$ & 3 & 1,1007 & 0,3669 & ** 17,87 & 0,0001 \\
\hline Resíduo & 19 & 0,3901 & 0,0205 & & \\
\hline TOTAL & 39 & 4,0464 & & & \\
\hline
\end{tabular}

Tabela 3.2. Análise de variância fixando o fator hora.

\begin{tabular}{lrrlrl}
\hline \multicolumn{1}{c}{$\mathrm{FV}$} & $\mathrm{GL}$ & \multicolumn{1}{l}{$\mathrm{SQ}$} & $\mathrm{QM}$ & $\mathrm{F}$ & $\mathrm{Pr}>\mathrm{F}$ \\
\hline Bloco & 1 & 0,0006 & 0,0006 & & \\
Horas & 3 & 0,2813 & 0,0938 & & \\
Conc(6) & 4 & 0,2374 & 0,0593 & 2,89 & 0,0502 \\
Conc(9) & 4 & 0,3247 & 0,0812 & $* 3,95$ & 0,0169 \\
Conc(12) & 4 & 0,6010 & 0,1503 & $* 7,32$ & 0,0010 \\
Conc(24) & 4 & 2,2113 & 0,5528 & $* * 26,93$ & 0,0001 \\
Resíduo & 19 & 0,3901 & 0,0205 & & \\
TOTAL & 39 & 4,0464 & & & \\
\hline
\end{tabular}

A segunda parte desta dissertação refere-se à comparação da linhagem MSE analisada anteriormente com uma linhagem de Aspergillus tolerante ao cádmio (CadG1). O período de 24 horas foi escolhido devido às diferenças significativas observadas na primeira parte do trabalho. Na Figura 9, observouse que houve uma queda na quantidade total de proteínas na linhagem MSE a partir de 0,005 mM, e esta continuou a decrescer até a concentração de 0,050 
mM. No entanto, apesar deste comportamento apresentado pela linhagem MSE, a linhagem CadG1 mostrou uma resposta oposta, na qual houve um aumento gradual das proteínas totais com o aumento das concentrações de cádmio.

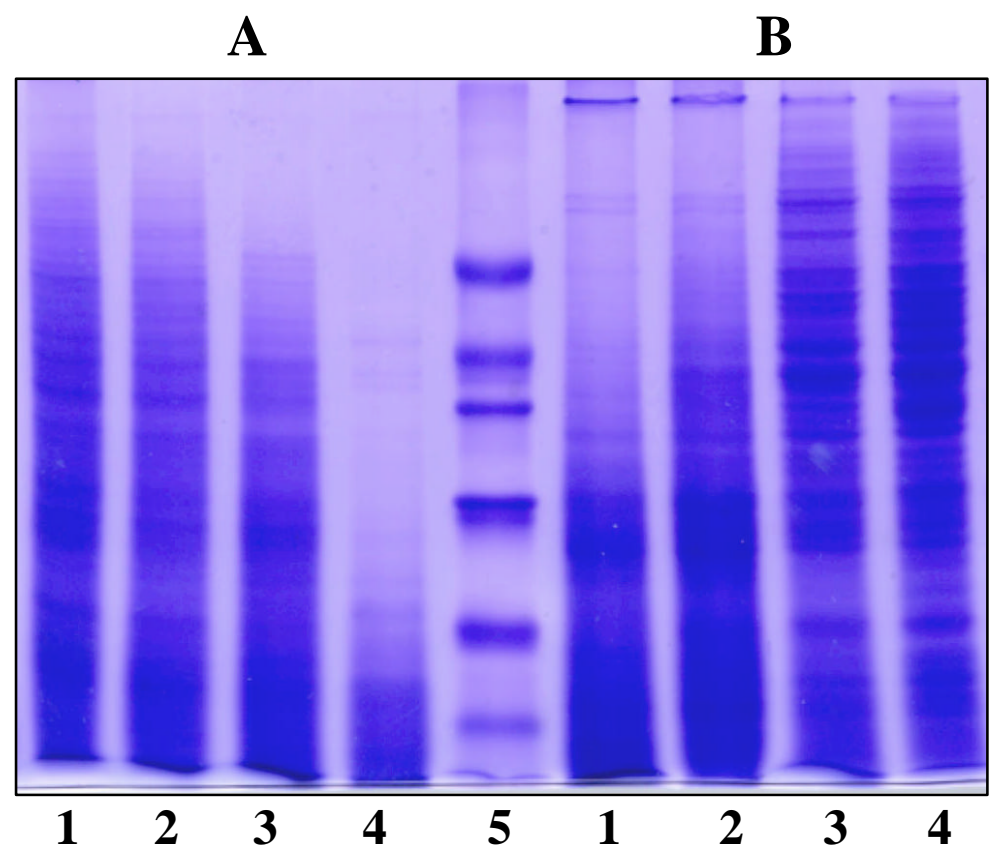

Figura 9 - Gel de proteínas SDS, onde: A e B, correspondem à linhagens MS E e CadG1, respectivamente; e as numerações correspondem (1) controle, (2) $0,005 \mathrm{mM}$, (3) 0,025 mM, (4) 0,050 mM e (5) padrão de peso molecular.

Com relação ao gel de atividade de SOD, a linhagem MSE apresentou as bandas A.II e A.III correspondentes à ba ndas II e III do experimento anterior. Neste experimento a resposta do fungo ao cádmio não foi observada, sendo que a isoforma A.ll praticamente não foi observada. A linhagem CadG1 apresentou duas isoformas B.I e B.II que representam isoformas diferentes das observadas na linhagem MSE como pode ser observado na Figura 10, quando se compara as isoformas com o padrão. A CadG1 apresentou uma resposta enzimática mais acentuada na isoforma B.II, na concentração de 0,025 mM, com posterior redução da atividade na concentração de 0,050 mM. 


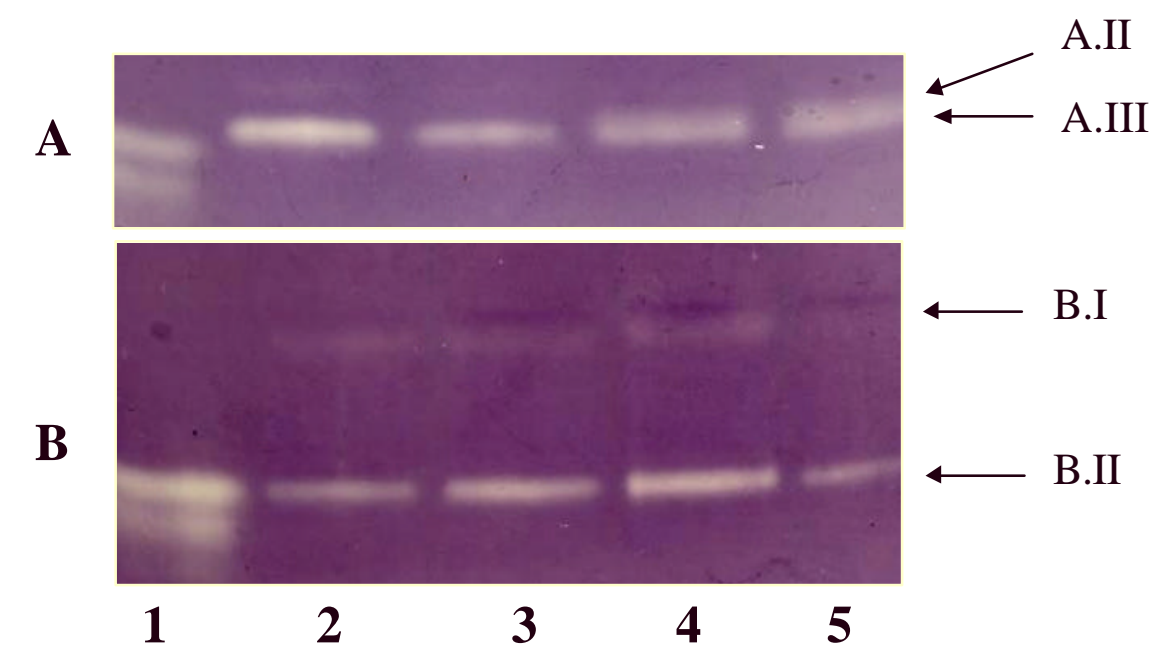

Figura 10 - Gel de atividade da enzima SOD, onde: A e B correspondem æ̀s linhagens MSE e CadG1, respectivamente. (1) padrão de peso molecular, (2) controle, (3) 0,005 mM, (4) $0,025 \mathrm{mM}$ e (5) $0,050 \mathrm{mM}$ de $\mathrm{CdCl}_{2}$. Os números romanos correspondem æ̀s isoformas da SOD.

O gel da enzima CAT (Figura 11) mostra um resultado semelhante ao da MSE, no qual houve um aumento significativo da isoforma A.I (corresponde à banda I do experimento anterior). A maior distância entre as bandas decorre do maior tempo de corrida do gel (6 horas, contra 4,5 horas do experimento anterior). A CadG1 apresentou quatro isoformas da CAT, no entanto foi observado um decréscimo significativo na atividade de CAT com o aumento da concentração administrada, em todas as isoformas. 


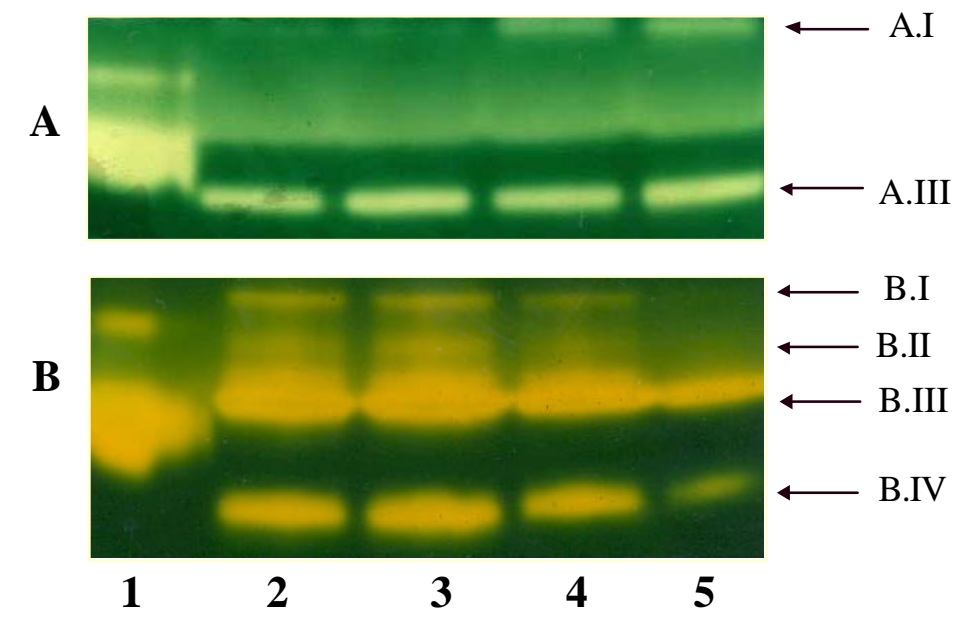

Figura 11 - Gel de atividade da enzima CAT, onde: A e B correspondem æ̀s linhagens MSE e CadG1, respectivamente. (1) padrão de peso molecular, (2) controle, (3) 0,005 mM, (4) 0,025 mM e (5) $0,050 \mathrm{mM}$ de $\mathrm{CdCl}_{2}$. Os números romanos correspondem às isoformas da CAT.

Assim como a MSE, a CadG1 também não apresentou atividade da enzima Guaiacol peroxidase nas condições estudadas, os números 1 e 2 correspondem à folha e raiz de milho e apresentaram resultados semelhantes com o primeiro experimento (Figura 12).

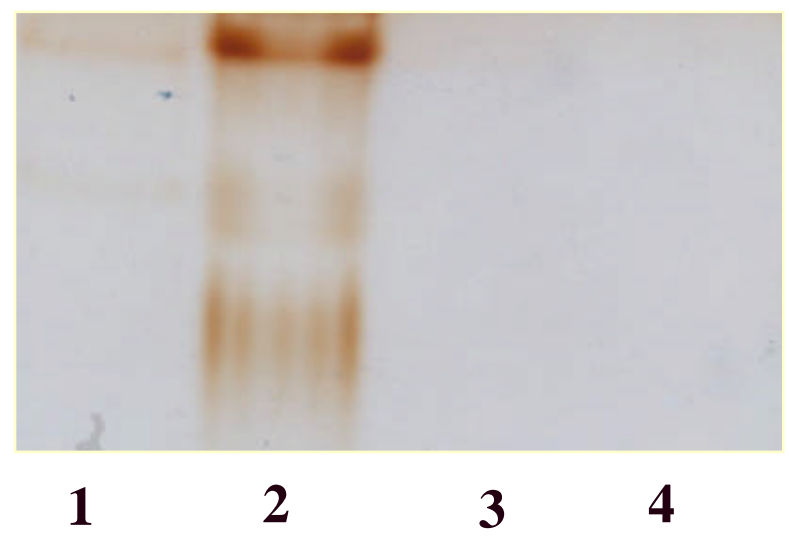

Figura 12 - Atividade de guaiacol peroxidase, onde: (1) folha de milho, (2) raiz de milho, (3) CadG1, no controle, e (4) CadG1 com 0,050 mM de Cd. 
Quanto à atividade de GR (Figura 13), ambas as linhagens responderam positivamente àpresença do $\mathrm{Cd}$. A linhagem MSE apresentou um aumento de 2,0 vezes, na atividade dessa enzima e a CadG1 aumentou sua atividade em 3,6 vezes, quando se comparou a concentração de $0,050 \mathrm{mM}$ com o controle. A análise de variância (Tabela 4) mostrou que houve diferença significativa entre as concentrações $(0 ; 0,005 ; 0,025$ e $0,050 \mathrm{mM}$ ), entre as linhagens (MSE e CadG1) e que estas apresentaram respostas significativamente diferentes. Este último dado pode ser observado pelas inclinações das retas, e foi constatado estatisticamente pela interação significativa entre os fatores analisados. A análise de variância da Tabela 4.1 mostra que no controle, as linhagens não diferiram entre si. Entretanto, na concentração de $0,005 \mathrm{mM}$ a diferença foi significativa a $5 \%$ e nas demais concentrações as linhagens diferiram a $1 \%$ de significância. Quando a linhagem foi fixada e se variou as concentrações (Tabela 4.2), observourse que a MSE e CadG1 apresentaram respostas significativas da enzima GR, a primeira a $5 \%$ de significância e a segunda a $1 \%$.

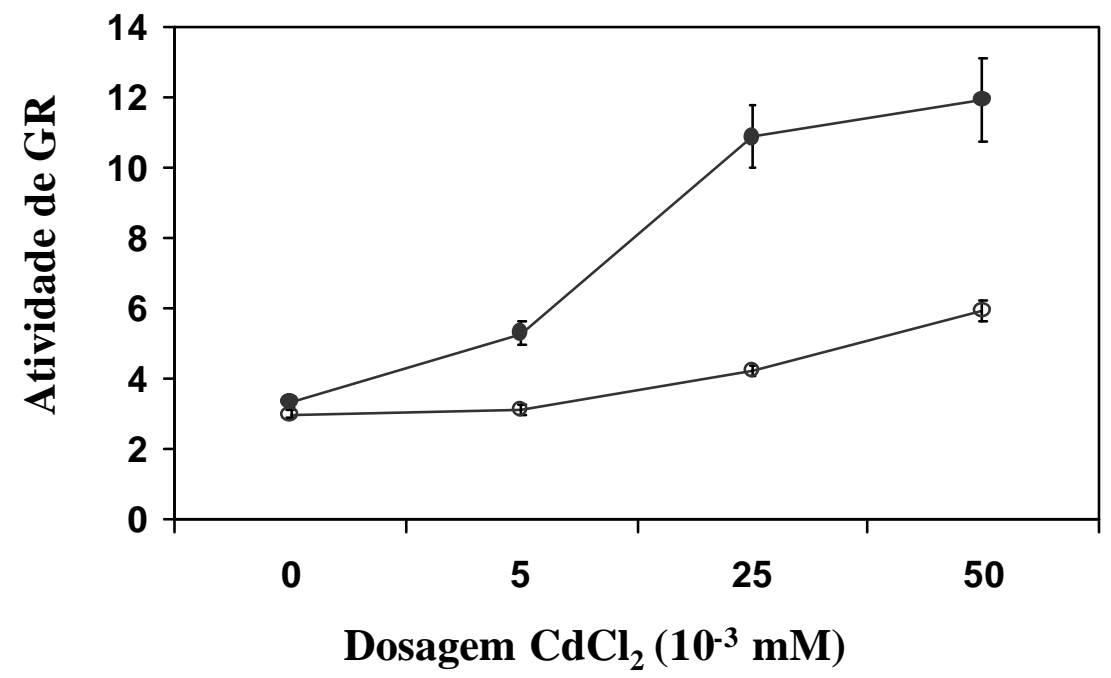

Figura 13 - Efeito das dosagens de $(0 ; 0,005 ; 0,025$ e 0,050 mM) de cádmio na atividade de GR do micélio das linhagens MSE e CadG1 no período de 24 horas, onde: O MSE, $\lambda$ CadG1. 
Tabela 4. Análise de variância dos dados provenientes da atividade de GR do micélio das linhagens MSE e CadG1 - dados não transformados.

\begin{tabular}{lrrrrr}
\hline \multicolumn{1}{c}{ FV } & GL & \multicolumn{1}{c}{ SQ } & QM & \multicolumn{1}{l}{$F$} & Pr $>$ F \\
\hline Linhagem & 1 & 57,7676 & 57,7676 & ${ }^{* *} 93,04$ & 0,0001 \\
Conc & 3 & 89,4405 & 29,8135 & ${ }^{* *} 48,02$ & 0,0001 \\
Linhag*Conc & 3 & 27,4958 & 9,1653 & ${ }^{* *} 14,76$ & 0,0013 \\
Resíduo & 8 & 4,9672 & 0,6209 & & \\
TOTAL & 15 & 179,6712 & & & \\
\hline
\end{tabular}

* 5 \% de significância; **1\% de significância; CV=13.18\%

Tabela 4.1. Análise de variância fixando o fator concentração.

\begin{tabular}{lrrrrr}
\hline \multicolumn{1}{c}{ FV } & GL & \multicolumn{1}{c}{ SQ } & \multicolumn{1}{c}{ QM } & \multicolumn{1}{l}{ F } & Pr $>$ F \\
\hline Concentração & 3 & 89,4405 & 29,8135 & & \\
Linhagem(0) & 1 & 0,1243 & 0,1243 & 0,20 & 0,6665 \\
Linhagem $(0,005)$ & 1 & 4,7873 & 4,7873 & $* 7,71$ & 0,0240 \\
Linhagem $(0,025)$ & 1 & 44,2558 & 44,2558 & $* * 71,28$ & 0,0001 \\
Linhagem (0,050) & 1 & 36,0961 & 36,0961 & $* * 58,13$ & 0,0001 \\
Resíduo & 8 & 4,9672 & 0,6209 & & \\
TOTAL & 15 & 179,6712 & & & \\
\hline
\end{tabular}

Tabela 4.2. Análise de variância fixando o fator hora.

\begin{tabular}{lrrrrr}
\hline \multicolumn{1}{c}{ FV } & GL & \multicolumn{1}{c}{ SQ } & \multicolumn{1}{c}{ QM } & \multicolumn{1}{c}{ F } & $\operatorname{Pr}>\mathrm{F}$ \\
\hline Linhagem & 1,00 & 57,7676 & 57,7676 & & \\
Conc(MSE) & 3,00 & 11,2115 & 3,7372 & 6,02 & 0,0190 \\
Conc(CadG1) & 3,00 & 105,7248 & 35,2416 & 56,76 & 0,0001 \\
Resíduo & 8,00 & 4,9672 & 0,6209 & & \\
TOTAL & 15,00 & 179,6712 & & & \\
\hline
\end{tabular}




\section{DISCUSSÃO}

\subsection{Peso Seco}

Nos resultados do presente trabalho observourse um aumento da esporulação e do peso seco nos tratamentos de exposição a $0,005 \mathrm{mM}$ de $\mathrm{Cd}$ e subseqüente decréscimo nesses parâmetros. A presença do $\mathrm{Cd}$ em baixas concentrações pode ser estimular o desenvolvimento das colônias na medida em que esse elemento pode eventualmente estar se complexando com componentes do meio de cultura, os quais, na ausência do $\mathrm{Cd}$ estariam seqüestrando o $\mathrm{Cu}$ disponível no meio para a formação de complexos, tornando-o não disponível para o microrganismo. Com a presença de pequenas quantidades de $\mathrm{Cd}\left(0,005 \mathrm{mM}\right.$ de $\left.\mathrm{CdCl}_{2}\right)$ mais $\mathrm{Cu}$ pode estar se mantendo disponível para a nutrição do fungo. Resposta semelhante foi encontrada por Cooley et al.(1986) que observou um estímulo de germinação do Aspergillus nidulans quando exposto à concentração de $\mathrm{Cd}$. Em dosagens maiores os efeitos deletérios do $\mathrm{Cd}$ sobre o metabolismo celular se fazem sentir e ocorre progressiva inibição do crescimento e esporulação do fungo.

\subsection{Proteínas Totais}

Entre as linhagens identificadas no presente trabalho, caracterizou-se uma com maiores índices de tolerância ao Cd que a linhagem MSE, a CadG1. Esta linhagem apresentou entre suas característica peculiares de resposta à exposição ao metal $\mathrm{Cd}$ um aumento na quantidade total de proteínas. Em 
Saccharomyces cerevisiae, Romandini et al. (1992), também estudando linhagens resistentes à exposiçào ao $\mathrm{Cd}$, observou um aumento significativo de proteínas totais, especialmente na linhagem SS1090, seguida da linhagens SS1189 e S.C., na presença do cádmio quando comparada com o controle.

\subsection{SOD}

Kapoor et al. (1990), estudando o fungo Neurospora crassa obtiveram resultados mostrando que o cádmio não induziu produção significativa da enzima SOD. Já em Romandini et al. (1992), constatourse um decréscimo nos valores de atividade da SOD, em linhagens de levedura S. cerevisiae, indicando um provável efeito inibitório deste metal na atividade de SOD, sendo a isoforma encontrada, a Cu/Zn-SOD. Por outro lado, Manzano et al. (1993), estudaram três linhagens dessa levedura e o cádmio não apresentou indução nos níveis da enzima SOD. Em Miszalski et al. (1996), foi estudado o efeito da adição do Cd no meio de cultura sobre o crescimento do micélio do Rhizopogon roseolus e se constatou que a exposição a esse metal provocou uma redução na atividade de SOD, sendo todas as isoformas encontradas, do tipo Mn-SOD. Neste trabalho, por sua vez, a linhagem MSE apresentou uma reduzida atividade de SOD na presença do $\mathrm{Cd}$, intensificada com relação ao controle em algumas das concentrações estudadas. Este dado está de acordo com os de Okamoto et al. (1996) que observaram aumento da atividade desta enzima na alga Tetraselmis gracilis, quando exposta a deste metal.

Zikic et al. (2001), estudaram grupos de peixes "goldfish", os quais foram expostos ao $\mathrm{Cd}$ e observaram que a atividade da SOD nas células vermelhas do sangue decresceu significativamente após o primeiro dia de exposição ao Cd. Entretanto, a atividade de SOD aumentou após 7 e 15 dias de tratamento. Após 15 dias, também foi encontrada elevada atividade de CAT nos eritrócitos dos peixes tratados. Estes resultados indicaram que o $\mathrm{Cd}$ causa estresse oxidativo e danos nos tecidos dos peixes expostos. 
Uma das respostas enzimáticas da linhagem MSE na presença do metal foi a intensificação da atividade da enzima SOD, embora tenha ocorrido com menor expressão em relação à demais enzimas apresentadas por este fungo. A linhagem CadG1, por sua vez, não apresentou resposta a esta enzima. É possível que isto tenha ocorrido porque a produção de $\mathrm{O}_{2}{ }^{-}$não tenha sido significativa em função da presença do cádmio e(ou) porque o período de 24 horas não foi suficiente para a indução de tal resposta.

\subsection{CAT}

Verduyn et al. (1988), afirmaram que apesar da pequena afinidade por $\mathrm{H}_{2} \mathrm{O}_{2}$, a CAT é uma enzima eficiente no sistema de desintoxicação do $\mathrm{H}_{2} \mathrm{O}_{2}$ do peroxisomo, porque este tem a vantagem de estar localizado no local onde 0 substrato é produzido. Entretanto, quando $\mathrm{o}_{2} \mathrm{H}_{2} \mathrm{O}_{2}$ tem origem extraperoxissomo, esta enzima pode prover apenas pequena proteção contra 0 $\mathrm{H}_{2} \mathrm{O}_{2}$. Sendo assim, na levedura Hansenula polymorpha, esses autores concluíram que a citocromo-c peroxidase tem um papel importante na desintoxicação do $\mathrm{H}_{2} \mathrm{O}_{2}$ exógeno.

Kapoor et al. (1990), estudando o fungo $N$. crassa, afirmaram que o $\mathrm{Cd}$ gera diretamente $\mathrm{O}_{\mathrm{b}} \mathrm{O}_{2}$ e as respostas enzimáticas estariam associadas a peroxidases. Romandini et al. (1992), em trabalho com S. cerevisiae, detectaram variações significativas na atividade de CAT quando tratadas com cádmio. Das três linhagens estudadas, uma delas apresentou aumento na atividade desta enzima quando tratada com cádmio, comparada com o controle, enquanto as demais linhagens não apresentaram resposta, nas mesmas condições.

Chen et al. (1995b), avaliaram os efeitos do Cd na taxa de crescimento, na atividade de CAT e no aumento de peroxisomos na levedura, Candida albicans. O crescimeno foi inibido com $1 \mathrm{mM}$ de $\mathrm{Cd}$ nas horas iniciais. $\mathrm{O}$ efeito tóxico do Cd na célula persistiu durante o crescimento. A atividade de CAT 
decresceu nas horas iniciais e aumentou em 2,6 vezes com 24 horas, em relação ao controle. O número de peroxisomos por célula tratada com $1 \mathrm{mM}$ de Cd aumentou 6 vezes em relação ao controle. O aumento de peroxissomos e 0 aumento da atividade de CAT devido à presença do Cd reforça a hipótese de que o Cd está relacionado com a indução de estresse oxidativo nas células.

Jamieson et al. (1996), por sua vez, estudaram efeito $\mathrm{H}_{2} \mathrm{O}_{2}$ em $C$. albicans e constataram que houve aumento significativo de CAT (16 vezes) em relação ao controle, e aumento da Cu/Zn-SOD em 2 vezes. Tais resultados deveram-se provavelmente a um mecanismo similar de defesa para a presença de ROS (ânion superóxido e $\mathrm{H}_{2} \mathrm{O}_{2}$ ), porém com menor indução para a enzima SOD. Fato semelhante pode estar acontecendo com a linhagem MSE, uma vez que nesta linhagem de $A$. nidulans, ocorreu estímulo da enzima SOD.

Emri et al. (1997), estudando a resposta de Penicillium chrysogenum, à exposição a peróxidos, constataram elevada atividade da CAT (e de GSH) e atribuíram a esse fato, a acentuada resistência deste organismo ao estresse oxidativo decorrente da exposição a peróxidos. Em Noventa-Jordão et al. (1999), demonstrou-se que o tratamento com $\mathrm{H}_{2} \mathrm{O}_{2}$ aumentou a viabilidade de germinação no $A$. nidulans após tratamento $\infty m$ calor (heat shock), enquanto mutantes deficientes em CAT foram mais sensíveis à exposição ao calor (50ํㅜ C). Concluiu-se que a defesa contra os efeitos letais do exposição ao calor pode estar correlacionada com a atividade do sistema de defesa contra 0 estresse oxidativo, e neste caso, àatividade de CAT.

Calera et al. (2000), caracterizaram a catalase B (CatB) do A. nidulans a qual é codificada pelo gene catB, está presente no micélio do fungo, e tem sua atividade aumentada durante a formação do conídio, mas, praticamente não é detectada nos esporos. A expressão do catB é induzida pelo $\mathrm{H}_{2} \mathrm{O}_{2}$ ou condições que gerem $\mathrm{H}_{2} \mathrm{O}_{2}$, não apresentando controle regulatório pós-transcricional. $\mathrm{O} A$. nidulans apresenta também a Catalase $\mathrm{A}$ (CatA), a qual é codificada pelo gene cat $A$, que é induzido especificamente durante a esporulação e em resposta a diferentes tipos de estresses. Na levedura $H$. polymorpha, Mannazzu et al. 
(2000), encontraram uma resposta positiva da atividade de CAT na presença do $\mathrm{Cu}$.

No presente trabalho, a linhagem MSE apresentou uma resposta significativa das enzimas CAT e GR, indicando que o $\mathrm{Cd}$ deve gerar $\mathrm{H}_{2} \mathrm{O}_{2}$ na célula. Os danos indiretos causados pelo $\mathrm{Cd}$ na célula do fungo, ou seja, a produção de ROS, sugerem que este gera uma quantidade significativa de $\mathrm{H}_{2} \mathrm{O}_{2}$ e em menor proporção de $\mathrm{O}_{2}^{-}$. A linhagem CadG1 apresentou aumento significativo somente da enzima GR, e portanto, deve estar utilizando outra peroxidase, que não a CAT, para eliminar os peróxidos formados na presença do cádmio.

\subsection{GR}

Stephen \& Jamieson (1996), mostraram que a glutationa é um antioxidante importante na levedura $S$. cerevisiae contra o estresse oxidativo. Este fato pode ser confirmado devido ao comportamento de mutantes deficientes na síntese de glutationa mostrarem-se hipersensíveis ao $\mathrm{H}_{2} \mathrm{O}_{2}$ e aos ânions superóxido, na fase exponencial e na fase estacionária do crescimento da cultura. Esses autores ressaltaram ainda que tanto as mudanças nos níveis de GSH como na relação GSH/GSSG podem ser sentidas pela célula e utilizadas como um sinal para induzir a resposta adaptativa ao estresse. Estas conclusões foram observadas também por Emri et al. (1997) ao estudarem o comportamento do $P$. chrysogenum na presença de hidroperóxidos.

Stephen \& Jamieson (1997), concluiram que apesar de sua natureza distinta, tanto $\mathrm{O}_{2} \mathrm{O}^{-\cdot}$ como $\circ \mathrm{H}_{2} \mathrm{O}_{2}$ regulam a expressão do gene GSH1 e demonstraram que a exposição a metais pesados, tais como Cd também resulta num aumento da expressão da GSH1. Este gene codifica a proteína GSH a qual tem sua produção estimulada para proteger a célula contra os danos causados por agentes oxidantes, metais pesados e pesticidas. Esta molécula constitue-se num metabólito ativo no combate æ̀s $\mathrm{ROS}\left(\mathrm{O}_{2} \cdot \mathrm{e} \mathrm{H}_{2} \mathrm{H}_{2}\right)$ via 
ciclo de Halliwell-Asada e assim, age como um eliminador de radicais livres, apresentando o grupo sulfidril ativo com poder de oxi-redução, reagindo com oxidantes para produzir GSSG. Com isso, diminui a relação GSH/GSSG. Para equilibrar esta relação, a GR tem sua atividade aumentada proporcionando a redução da GSSG para a forma GSH. Carmem Pinto et al. (1984), observaram que uma relação muito alta de GSH/GSSG pode inativar a enzima GR.

Em plantas, Stroinski et al. (1999), estudaram o comportamento de tubérculos de batata (Solanum tuberosum L.) na presença do $\mathrm{Cd}$. O aumento da atividade de GR foi observada em tecidos menos resistentes ao Cd após 24 horas de exposição e foi menor nas amostras mais resistentes. Em elevadas concentrações ocorreu um processo de inativação da GR pelo Cd. Balestrasse et al. (2001), estudou o sistema de defesa antioxidante dos nódulos e raízes da soja (Glycine max L.) em plantas sujeitas a concentrações diferentes de $\mathrm{Cd}$, nas quais foram detectadas formação de peroxidação lipídica. Nos nódulos houve um aumento na atividade da enzima CAT. O mecanismo de defesa enzimático das raízes mostraram um aumento significativo na atividade da enzima GR nos tratamentos com baixa concentração de $\mathrm{Cd}$, enquanto a atividade desta enzima decresceu com as concentrações mais altas de Cd. Vitória et al. (2001), observaram um aumento nas atividades das enzimas GR e CAT em raízes e folhas de rabanete (Raphanus sativus L.) com a adição do $\mathrm{Cd}$.

\subsection{Guaiacol Peroxidase}

Não há, até o momento da finalização do presente trabalho, referência sobre a presença de guaiacol peroxidase em fungos. As linhagens não apresentaram a enzima guaiacol peroxidase e na literatura foram relatados casos em plantas como os citados na revisão. 


\section{CONCLUSÕES}

\subsection{Linhagem MSE de A. nidulans}

- Apresentou uma redução significativa em seu peso seco quando exposta por 24 horas a $0,050 \mathrm{mM}$ de $\mathrm{CdCl}_{2}$, comparado com o padrão.

- Foi observado um ligeiro aumento de peso seco com a dosagem de 0,005 $\mathrm{mM}$ de $\mathrm{CdCl}_{2}$, em todos os períodos de tempo estudados (6, 9, 12 e 24h).

- Apresentou como principais respostas à presença do cádmio aumento da atividade das enzimas CAT e GR.

- Em termos quantitativos, a GR apresentou um aumento de 2,7 vezes em sua atividade quando exposta por 24 horas a $0,050 \mathrm{mM}$ de $\mathrm{CdCl}_{2}$, comparada com o padrão.

- Não apresentou atividade da enzima guaiacol peroxidase, nas condições estudadas.

\subsection{Linhagem CadG1 de Aspergillus sp.}

- A principal enzima antioxidante identificada como resposta à exposição ao $\mathrm{Cd}$, foi a GR, constatando-se um aumento na atividade de 3,6 vezes quando exposta por 24 horas a $0,050 \mathrm{mM}$ de $\mathrm{CdCl}_{2}$, comparada com o padrão.

- Apresentou uma redução de atividade nas enzimas CAT e SOD.

- Não apresentou atividade enzima guaiacol peroxidase, nas condições estudadas. 


\subsection{Considerações Finais}

Face aos resultados encontrados, de intensa resposta à exposição ao metal pesado $\mathrm{Cd}$ em duas linhagens de Aspergillus, sugere-se a realização de novos estudos abrangendo a enzima glutationa peroxidase e a proteínas glutationa e metalotioneína. Tais pesquisas podem estudar não apenas essas, mas também outras linhagens e espécies de fungos filamentosos, em relação ao $\mathrm{Cd} \mathrm{e(ou)} \mathrm{outros} \mathrm{metais} \mathrm{pesados,} \mathrm{com} \mathrm{o} \mathrm{intuito} \mathrm{de} \mathrm{melhor} \mathrm{caracterizar} \mathrm{os}$ sistemas metabólicos e genéticos envolvidos nestes processos. 


\section{REFERÊNCIAS BIBLIOGRÁFICAS}

ALSCHER, R.G.; DONAHUE, J.L.; CRAMER, C.L. Molecular responses to reactive oxygen species: multifaceted changes in gene expression. In: KOK, L.J.; STULEN, I. (Ed.) Responses of plant metabolism to air pollution and global change. Leiden: Backhuys Publishers, 1998. p.233-240.

ANGELOVA, M.B.; PASHOVA, S.B.; SLOKOSKA, L.S. Comparison of antioxidant enzyme biosynthesis by free and immobilized Aspergillus nidulans cells. Enzyme and Microbial Technology, v.26, p.544-549, 2000.

AZEVEDO, J.L.; COSTA, S.O.P. Exercícios práticos de genética. São Paulo: Nacional, 1973. 288p.

AZEVEDO, R.A.; ALAS, R.M.; SMITH, R.J.; LEA, P.J. Response of antioxidant enzymes to transfer from elevated carbon dioxide to air and ozone fumigation, in leaves and roots of wild-type and a catalase-deficient mutant of barley. Physiologia Plantarum, v.104, p.280-292, 1998.

BALESTRASSE, K.B.; GARDEY, L.; GALLEGO, S.M.; TOMARO, M.L. Response of antioxidant defence system in soybean nodules and roots subjected to cadmium stress. Australian Journal of Plant Physiology, v.28, p.497-504, 2001. 
BHATTACHARJEE, S. Membrane lipid peroxidation, free radical scavengers and ethylene evolution in Amaranthus as affected by lead and cadmium. Biologia Plantarum, v.40, n.1, p.131-135, 1997/98.

BOWLER, C.; VAN MONTAGU, M.; INZÉ, D. Superoxide-dismutase and stress tolerance. Annual Review of Plant Physiology and Plant Molecular Biology, v.43, p.83-116, 1992.

BRADFORD, M.M. A rapid and sensitive method for the quantitation of microgram quantities of protein utilizing the principle of protein-dye binding. Analytical Biochemistry, v.72, p.248-259, 1976.

CALERA, J.A.; SÁNCHEZ-WEATHERBY, J.; LÓPES-MEDRANO, R.; LEAL, F. Distinctive properties of the catalase $B$ of Aspergillus nidulans. FEBS Letters, v.475, p.117-120, 2000.

CAMPA, A. Biological roles of plant peroxidases: known and potential function. In: EVERSE, J.; EVERSE, K.E.; GRISHAM, M.B. (Eds.). Peroxidases in Chemistry and Biology. Boca Raton: CRC Press, 1991. p. 25-50.

CHAOUI, A.; GHORBAL, M.H.; EL FERJANI, E. Effects of cadmium-zinc interactions on hydroponically grown bean (Phaseolus vulgaris L.). Plant Science, v.126, p.21-28, 1997.

CHEN, S.L.; KAO, C.H. Glutathione reduces the inhibition of rice seedlings root growth caused by cadmium. Plant Growth Regulation, v.16, p.249-252, 1995a. 
CHEN, T.; LI, W.; SCHULZ, P.J.; FURST, A.; CHIEN, P.K. Induction of peroxisome proliferation and increase of catalase activity in yeast, Candida albicans, by cadmium. Biological Trace Element Research, v.50, n.2, p.125-133, 1995b.

COOLEY, R.N.; THURMAN, D.A.; TOMSETT, A.B. Molecular mechanisms of heavy-metal tolerance in Aspergillus nidulans. Heredity, v.57, p.133-134, 1986.

CREISSEN, G.P.; EDWARDS, E.A.; MULLINEAUX, P.M. Glutathione reductase and ascorbate peroxidase. In: FOYER, C.H.; MULLINEAUX, P.M. (Ed.) Causes of photoxidative stress and amelioration of defence systems in plants. Boca Raton: CRC Press, 1994. p.343-364.

DÖNMEZ, G.; AKSU, Z. The effect of copper (II) ions on the growth and bioaccumulation properties of some yeasts. Process Biochemistry, v.35, p.135-142, 1999.

EMRI, T.; POCSI, I.; SZENTIRMAI, A. Glutathione metabolism and protection against oxidative stress caused by peroxides in Penicillium chrysogenum. Free Radical Biology and Medicine, v.23, n.5, p.809-814, 1997.

FERREIRA, R.R. Resposta antioxidativa de plantas de soja ao metal pesado cádmio. Piracicaba, 2000. 89p. Tese (Mestrado) - Escola Superior de Agricultura "Luiz de Queiroz", Universidade de São Paulo.

FIELDES, M.A.; GERHARDT, K.E. Flax guaiacol peroxidases can be used to illustrate the possibility of misinterpreting the effects of stress on the activity of developmentally regulated enzymes. Plant Science, v.132, p.89-99,1998. 
FRUGOLI, J.A.; ZHONG, H.H.; NUCCIO, M.L.; McCOURT, P.; McPEEK, M.A.; THOMAS, T.L.; McCLUNG, C.R. Catalase is encoded by a multigene family in Arabidopsis thaliana (L.) Heynh. Plant Physiology, v.112, p.327-336, 1996.

FUJII, T.; HAMAOKA, R.; FUJII, J.; TANIGUCHI, N. Redox capacity of cells affects inactivation of glutathione reductase by nitrosative stress. Archives of Biochemistry and Biophysics, v.378, p.123-130, 2000.

GADD, G.M. Biosorption. Chemistry and Industry, v.2, p.421-426, 1990.

GADD, G.M.; WHITE, C. Microbial treatment of metal pollution: a working biotechnology? Trends in BioTechnology, v.11, p.353-359, 1993.

GALLI, U.; SCHÜEPP, H.; BRUNOLD, C. Thiols in cadmium-and coppertreated maize (Zea mays L.). Planta, v.198, p.139-143, 1996.

GHOSHROY, S.; FREEDMAN, K.; LARTEY, R.; CITOVSKY, V. Inhibition of plant viral systemic infection by non-toxic concentrations of cadmium. The Plant Journal, v.13, n.5, p.591-602, 1998.

GIMENO-GARCÍA, E.; ANDREU, V.; BOLUDA, R. Heavy metals incidence in the application of inorganic fertilizers and pesticides to rice farming soils. Environmental Pollution, v.92, n.1, p.19-25, 1996.

GOLDBERG, R.; IMBERTY, A.; LIBERMAN, M.; PRAT, R. Relationship between peroxidase activities and cell wall plasticity, In: GREEPIN, H.; PENEL, C.; GASPER, T. (Eds.). Molecular and physiological aspects of plant peroxidases, 1986. p.208-220. 
GRISEBACH, H. Lignins. In: CONN, E.E. (Ed.). The biochemistry of plants, New York: Academic Press, 1981. v.7, p.457-478.

IRETSKAYA, S.N.; CHIEN, S.H.; MENON, R.G. Effect of acidulation of high cadmium containing phosphate rocks on cadmium uptake by upland rice. Plant and Soil, v.201, p.183-188, 1998.

IWAMOTO, M.; MAEKAWA, M.; SAITO, A. Evolutionary relationship of plant catalase genes inferred from exon-intron structures: isozyme divergence after the separation of monocots and dicots. Theoretical and Applied Genetics, v.97, p.9-19, 1998.

JAMIESON, D.J., STEPHEN, D.W.S.; TERRIÈRE, E.C. Analysis of the adaptive oxidative stress response of Candida albicans. FEMS Microbiology Letters, v.138, p.83-88, 1996.

KAPOOR, A.; VIRARAGHAVAN, T.; CULLIMORE, D.R. Removal of heavy metals using the fungus Aspergillus nidulans. Bioresource Technology, v.70, p.95-104, 1999.

KAPOOR, M.; SREENIVASAN, G.M.; GOEL, N.; LEWIS, J. Development of thermotolerance in Neurospora crassa by heat shock and other stresses eliciting peroxidase induction. Journal of Bacteriology, v.172, n.5, p.27982801, 1990.

KEFALA, M.I.; ZOUBOULIS, A.I.; MATIS, K.A. Biosorption of cadmium ions by Actinomycetes and separation by flotation. Environmental Pollution, v.104, p.283-293, 1999. 
KISTLER, M.; SUMMER, K.H.; ECKARDT, F. Isolation of glutathione deficient mutants of the yeast Saccharomyces cerevisiae. Mutation Research, v.173, p.117-120, 1986.

LAEMMLI, U.K. Cleavage of structural proteins during the assembly of the head of bacteriophage T4. Nature, v.227, p.680-685, 1970.

LAGRIFFOUL, A.; MOCQUOT, B.; VANGRONSVELD, J.; MENCH, M. Cadmium toxicity effects on growth, mineral and chlorophyll contents, and activities of stress related enzymes in young maize plants (Zea mays L.). Plant and Soil, v.200, p.241-250, 1998.

LEA, P.J.; WELLBURN, F.A.M.; WELLBURN, A.R.; CREISSEN, G.P.; MULLINEAUX, P.M. Use of transgenic plants in the assessment of responses to atmospheric pollutants. In: KOK, L.J.; STULEN, I. (Ed.). Responses of plant metabolism to air pollution and global change. Leiden: Backhuys Publishers, 1998. p.241-250.

LEE, K.C.; CUNNINGHAN, B.A.; PAULSEN, G.M.; LIANG, G.H.; MOORE, R.B. Effects of cadmium on respiration rate and activities of several enzymes in soybean seedlings. Physiologia Plantarum, v.36, p.4-6, 1976.

LESSER, L.; STOCHAJ, W.R. Protoadaptation and protection against active forms of oxygen in the symbiotic prokaryote Prochloron sp. and its ascidian host. Applied Environmental Microbiology, v. 56, p.1530-1535, 1990.

LI, Z.S.; LU, Y.P.; ZHEN, R.G.; SZCZYPKA, M.; THIELE, D.; REA, P.A. A new pathway for vacuolar transport of bis (glutathionato) cadmium. Proceedings of the National Academy of Sciences of the United States of America, v.94, p.42-47, 1997. 
MALAN, H.L.; FARRANT, J.M. Effects of the metal pollutants cadmium and nickel on soybean seed development. Seed Science Research, v.8, p.445453, 1998.

MALANGA, G.; KOZAK, R.G.; PUNTARULO, S. Nacetylcysteine-dependent protection against UV-B damage in two photosynthetic organisms. Plant Science, v.141, p.129-137, 1999.

MALAVOLTA, E. Fertilizantes e seu impacto ambiental: micronutrientes e metais pesados: mitos, mistificação e fatos. São Paulo: Produquímica, 1994. 153p.

MALLICK, N.; MOHN, F.H. Reactive oxygen species: response of algal cells. Journal of Plant Physiology, v.157, p.183-193, 2000.

MALLICK, N.; RAI, L.C. Response of the antioxidant systems of the nitrogen fixing cyanobacterium Anabaena doliolum to copper. Journal of Plant Physiology, v.155, p.146-149, 1999.

MANNAZZU, I.; GUERRA, E.; FERRETTI, R.; PEDICONI, D.; FATICHENTI, F. Vanadate and copper induce overlapping oxidative stress responses in the vanadate-tolerant yeast Hansenula polymorpha. Biochimica et Biophysica Acta, v.1475, p.151-156, 2000.

MANZANO, M.; ROMANDINI, P.; DEBERTOLDI, M.; BELTRAMINI, M.; SALVATO, B.; COZZANI, I. Interaction among heavy-metals and methanol affecting superoxide-dismutase activity in Saccharomyces cerevisiae. Comparative Biochemistry and Physiology - Pharmacology, Toxicology and Endocrinology, v.105, n.2, p.175-178, 1993. 
MATTSON, M.P. Answering the old age question. Chemistry \& Industry, v.20, p.843-848, 1998.

McCULLY, K.S.; FORBES, E. The use of pfluorphenilalanina with "master" strain of Aspergillus nidulans form assigning gene of to linkage groups. Genetical Research, v.6, p.352-359, 1965.

MEISTER, A. Selective modification of glutathione metabolism. Science, v.220, p.472-477, 1983.

MELO, W.J.; MARQUES, M.O.; SILVA, F.C.; BOARETTO, A.E. Uso de Resíduos Sólidos Urbanos na Agricultura e Impactos Ambientais. In: CONGRESSO BRASILEIRO DE CIÊNCIA DO SOLO, 26., Rio de Janeiro, 1997. Resumos. 28p.

MISZALSKI, Z.; BOTTON, B.; TURNAU, K. New SOD isoform in Rhizopogon roseolus (Corda in Sturm) in the presence of cadmium. Acta Physiologiae Plantarum, v.18, n.2, p.129-134, 1996.

NASCIMENTO, C.W.A.; PEREIRA, J.B.M. Absorção e distribuição de cádmio e micronutrientes em cultivares de feijoeiro expostas a doses de cádmio. Pesquisa Agropecuária Brasileira, v.32, n.12, p.1303-1308, 1997.

NIYOGI, K.K. Photoprotection revisited: genetic and molecular approaches. Annual Review of Plant Physiology and Plant Molecular Biology, v.50, p.333-359, 1999. 
NOVENTA-JORDÃO, M.A.; COUTO, R.M.; GOLDMAN, M.H.; AGUIRRE, J.; IYER, S.; CAPLAN, A.; TERENZI, H.F.; GOLDMAN, G.H. Catalase activity is necessary for heat-shock recovery in Aspergillus nidulans germlings. Microbiology, v.145, p.3229-3234, 1999.

OKAMOTO, O.K.; COLEPICOLO, P. Response of superoxide dismutase to pollutant metal stress in the marine dinoflagellate Gonyaulax polyedra. Comparative Biochemistry and Physiology - Pharmacology, Toxicology and Endocrinology, v.119, p.67-73, 1998.

PANAGOPOULOS, I.; BORNMAN, J.F.; BJORN, L.O. Effects of ultraviolet radiation and visible light on growth, fluorescence induction, ultraweak luminescence and peroxidase activity in sugar beet plants. Journal of Photochemistry and Photobiology, v.8, p. 73-87, 1990.

PANAGOPOULOS, I.; BORNMAN, J.F.; BJORN, L.O. The effect of UV-B and UV-C radiation on Hibiscus leaves determined by ultraweak luminescence and fluorescence induction, Physiologia Plantarum, v.76, p.461-465, 1989.

PENNINCKX, M. A short review on the role of glutathione in the response of yeasts to nutritional, environmental, and oxidative stresses. Enzyme and Microbial Technology, v.26, p.737-742, 2000.

PINTO, C.M.; MATA, A.M.; LOPEZ-BAREA, J. Reversible inactivation of Saccharomyces cerevisiae Glutathione redutase under reducing conditions. Archives of Biochemistry and Biophysics, v.228, n.1, p.1-12, 1984.

PONTECORVO, G.; ROPER, J.A.; HEMMONS, L.M.; MacDONALD, K.D.; BUFTON, A.W.J. The genetics of Aspergillus nidulans. Advances in Genetics, v.5, p.141-238, 1953. 
PRASAD, M.N.V. Cadmium toxicity and tolerance in vascular plants. Environmental and Experimental Botany, v.35, n.4, p.525-545, 1995.

RADY, A.A.; EL-SHEEKH, M.M.; MATKOVICS, B. Temperature shift-induced changes in the antioxidant enzyme system of cyanobacterium Synechosystis PCC 6803. International Journal Biochemistry, v.26, p.433-435, 1994.

RICE-EVANS, C.A.; DIPLOCK, A.T.; SYMONS, M.C.R. Techniques in free radical research. In: BURDON, R.H.; VAN KNIPPENBERG, P.H. (Ed.). Laboratory techniques in biochemistry and molecular biology. Amsterdam: Elsevier, 1991. v.22, 291p.

ROMANDINI, P.; TALLANDINI, L.; BELTRAMINI, M.; SALVATO, B.; MANZANO, M.; DE BERTOLDI, M.; ROCCO, G.P. Effects of copper and cadmium on growth, superoxide dismutase and catalase activities in different yeast strains. Comparative Biochemistry and Physiology, v.103, n.2, p.255-262, 1992.

ROSSI, C.; PADILHA, P.M.; PADILHA, C.C.F. Absorção de Cádmio e crescimento de feijoeiro (Phaseolus vulgaris, L. cv carioca). Scientia Agricola, v.55, n.2, p.332-337, 1998.

SCANDALIOS, J.G. Oxygen stress and superoxide dismutases. Plant Physiology, v.101, p.7-12, 1993.

SCANDALIOS, J.G. Regulation and properties of plant catalases. In: FOYER, C.H.; MULLINEAUX, P. Causes of photooxidative stress and amelioration of defense systems in plants. Boca Raton: CRC Press, 1994. p.275-315. 
SCHICKLER, H.; CASPI, H. Response of antioxidative enzymes to nickel and cadmium stress in hyperaccumulator plants of the genus Alyssum. Physiologia Plantarum, v.105, p.39-44, 1999.

SEHMER, L.; DIZENGREMEL, P. Contribution to subcellular localization of superoxide dismutase isoforms of spruce needles and oak leaves. Journal of Plant Physiology, v.153, p.545-551, 1998.

SKADSEN, R.W.; SCHULZE-LEFERT, P.; HERBST, J.M. Molecular cloning, characterization and expression analysis of two catalase isozyme genes in barley. Plant Molecular Biology, v.29, p.1005-1014, 1995.

SMIRNOFF, N. The role of active oxygen in the response of plants to water deficit and desiccation. New Phytology, v.125, p.27-58, 1993.

STAMLER, J. S. Redox signaling: Nitrosylation and related target interactions of nitric oxide. Cell, v.78, p.931-936, 1994.

STEPHEN, D.W.S.; JAMIESON, D.J. Amino acid-dependent regulation of the Saccharomyces cerevisiae GSH1 gene by hidrogen peroxide. Molecular Microbiology, v.23, n.2, p.203-210, 1997.

STEPHEN, D.W.S.; JAMIESON, D.J. Glutathione is an important antioxidant molecule in the yeast Saccharomyces cerevisiae. FEMS Microbiology Letters, v.141, p.207-212, 1996.

STROINSKI, A.; KUBIS, J.; ZIELEZINSKA, M. Effect of cadmium on glutathione reductase in potato tubers. Acta Physiologiae Plantarum, v.21, n.3, p.201207, 1999. 
TEKCHANDANI, S.; GURUPRASAD, K.N. Modulation of a guaiacol peroxidase inhibitor by UV-B in cucumber cotyledons. Plant Science, v.136, p.131-137, 1998.

VALLEJOS, C.E. Enzyme activity staining. In: TANKSLEY, S.D.; ORTON, T.J. (Ed.). Isozymes in plant genetics and breeding, part A. Amsterdam: Elsevier, 1983. p.469-516.

VEGLIO, F.; BEOLCHINI, F. Removal of metals by biosorption: a review. Hydrometallurgy, v.44, p.301-316, 1997.

VERDUYN, C.; GIUSEPPIN, M.L.F.; SCHEFFERS, A.; VAN DIJKEN, J.P. Hydrogen peroxide metabolism in yeasts. Applied and Environmental Microbiology, v.54, p.2086-2090, 1988.

VITÓRIA, A.P.; LEA, P.J.; AZEVEDO, R.A. Antioxidant enzymes responses to cadmium in radish tissues. Phytochemistry, v.57, p.701-710, 2001.

VOET, D.; VOET, J.G. Biochemistry. 2.ed. New York: John Wiley, 1995. $1361 \mathrm{p}$.

WAALKES, M. P. Cadmium carcinogenesis in review. Journal of Inorganic Biochemistry, v.79, p.241-244, 2000.

WAIHUNG, L.; CHUA, H.; LAM, K-H.; BI, S-P. A comparative investigation on the biosorption of lead by filamentous fungal biomass. Chemosphere, v.39, p.2723-2736, 1999. 
WINGSLE, G.; GARDESTRÖM, P.; HÄLLGREN, J.; KARPINSKI, S. Isolation, purification, and subcellular localization of isozymes of superoxide dismutase from scots pine (Pinus sylvestris L.) needles. Plant Physiology, v.95, p.2128, 1991.

WOODBURY, W.; SPENCER, A.K.; STAHMANN, M.A. An improved procedure using ferrycianide for detecting catalase isosymes. Analytical Biochemistry, v.44, n.1, p.301-305, 1971.

ZIKIC, R.V.; STAJN, A.S.; PAVLOVIC, S.Z.; OGNJANOVIC, B.I.; SAICIC, Z.S. Activities of superoxide dismutase and catalase in erythrocytes and plasma transaminases of goldfish (Carassius auratus gibelio Bloch.) exposed to cadmium. Physiological Research, v.50, n.1, p.105-111, 2001. 